\title{
The cyclical over-accumulation and destruction of capital
}

\section{Business cycles}

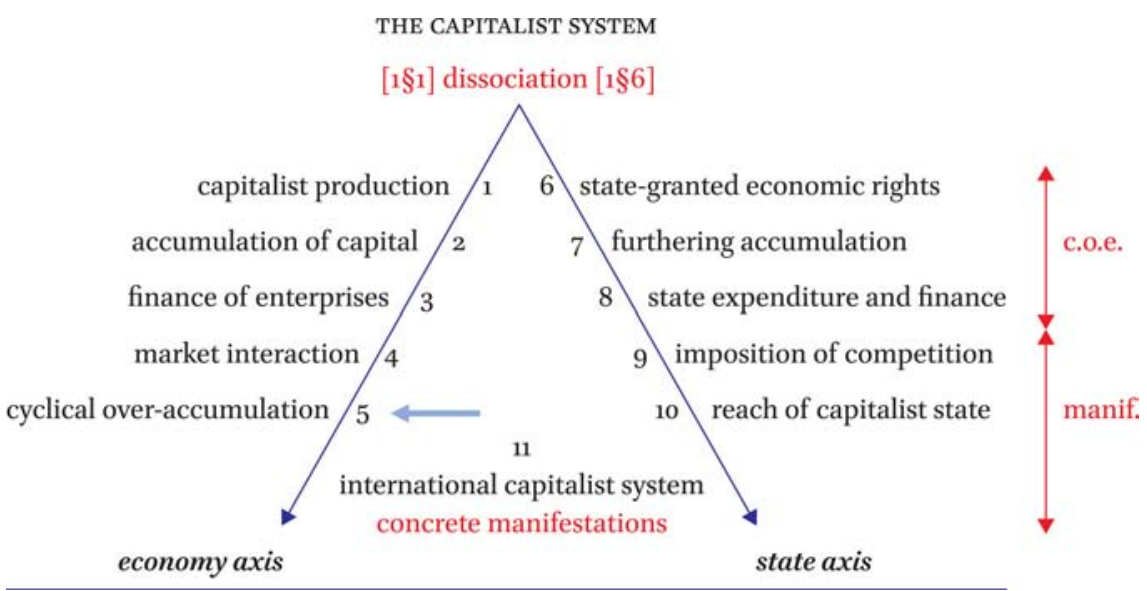

Note: 'c.o.e.' abbreviates conditions of existence and 'manif.' manifestations.

\section{Contents}

\section{Introduction $\quad 245$}

Division 1. The internal profit of enterprises: surplus-value net of its distribution to external financiers $\quad 246$

$5 \S 1 \quad$ The rate of integral profit and the rate of internal profit 247

$5 \S 2$ The realisation of surplus-value $(\Pi)$, and the internal profit $(\mathrm{R})$ as a distributional result 248

$5 \S 3$ Determinants of saving by labour and consumption by capital owners 249

$5 \S 4$ External finance: the PVF, the RPVF and the rate of interest $25^{\circ}$

$5 \S 5$ Determinants of investment 251

$5 \S 6$ A condensed macroeconomic sequence 253

Division 2. The cyclical over-accumulation and destruction of capital $\quad 256$

$5 \S 7 \quad$ The phase-wise stratified cyclical movement of capital: preliminaries $\quad 256$

$5 \S 8$ Cyclical movement (1): from expansion to stagnation $\quad 258$

(C) GEERT REUTEN, 2019 | DOI:10.1163/9789004392809_007

This is an open access chapter distributed under the terms of the prevailing CC-BY-NC-ND License at the time of publication. 
$5 \S 9$ Cyclical movement (2): from stagnation to contraction and renewed expansion 264

Summary and conclusions $\quad 279$

Appendix 5a. On the particular structural background of the 2008 crisis $\quad 281$ Introduction and synopsis 281

$5^{\mathrm{A}-1} \quad$ The general constellation $\quad 282$

$5^{\mathrm{A}-2}$ From declining savings out of wages to 'colonization of the future' 284

$5^{\mathrm{A}-3}$ Conjunction of interests 286

$5^{\mathrm{A}-4}$ Course of the 2008 crisis and its crisis-ridden aftermath $\quad 288$

5A-5 Problem of stagnation not resolved (2018) 288

$5^{\mathrm{A}-6}$ Modification of the 'normal' course of the business cycle 289

Appendix 5B. stratified production and Marx's unfinished theory of the cyclical movement of capital 290

List of figures chapter $5 \quad 292$ 


\section{Introduction}

This chapter reaches the most concrete level of the exposition of the capitalist economy in this book. Chapters 1-3 presented the necessary conditions of existence of the capitalist economy - with the state yet being bracketed. Chapter 4 presented the concrete manifestation of the earlier exposition in the market interaction between enterprises as predicated on the stratified structure of production. Like that chapter the current one presents no conditions of existence of the capitalist economy. Rather it presents the concrete manifestation of all of the previous exposition (Chapters 1-4) in the diachronic cyclical movement of capital.

The alternation of economic expansion and contraction - commonly referred to as 'the business cycle' - is an empirical phenomenon that mainstream economists have sought to explain by an alternation of merely contingent 'exogenous shocks'. This chapter shows that the production and accumulation of capital in the form of its cyclical movement derives from the capitalist system's immanent forces.

In brief it will be set out how cyclically recurrent barriers to a continuous accumulation of capital develop in the second half of the economic upswing. These are next violently resolved in the recession. Whereas system-immanent forces engender the accumulation of capital, the same forces generate overaccumulation of capital in the form of excessive overcapacity. This is a constellation that cannot be simply corrected and that leads to reactions that are perverse to the accumulation of capital. In presenting this constellation I build on the financial determinants of accumulation (PVF and RPVF) and the macroeconomic determinants of the realisation of surplus-value (including the obstacle of savings). Their concretisation will be assembled by the stratified structure of production, which is now lifted to a macroeconomic level. (Division 2.)

The exposition in this chapter synthesises many of the threads of the earlier exposition at this concrete level. However, as economic reality is inevitable always actual in some phase of this movement (one phase of the business cycle), its exposition is also a concrete synthesis of the earlier exposition.

In preparation for the main exposition in this chapter, Division 1 presents a number of concretising concepts. The cyclical movement of capital itself is presented in Division 2 (see Scheme 5.1). 
SCHEME 5.1 The cyclical over-accumulation and destruction of capital (outline Chapter 5)

Production, Accumulation, Finance and Stratification

[Chapters 1-4]

.mę.

\begin{tabular}{|c|}
$\begin{array}{c}\text { The internal profit of enterprises } \\
\text { surplus-value net of its distribution to external financiers } \\
{\left[5^{\mathrm{D}} 1\right]}\end{array}$ \\
\hline .M. \\
\hline The cyclical over-accumulation and destruction of capital \\
{$\left[5^{\mathrm{D} 2}\right]$}
\end{tabular}

Appendix 5 A. On the particular structural background of the 2008 crisis

Appendix ${ }_{5}$ B. Stratified production and Marx's unfinished theory of the cyclical movement of capital

Legend

.mę. concretising mode of existence

.M. concrete manifestation

Division 1. The internal profit of enterprises: surplus-value net of its distribution to external financiers

Preparatory concretising concepts for ${ }_{5} D_{2}$

This division is a conceptually preparatory one for the outline of the cyclical movement of capital in Division 2. The investment of enterprises will be seen to be a main determinant of the cyclical movement of capital (Division 2). One main factor that determines investment decisions is the 'internal profit' of enterprises - that is, the surplus-value after a share of it has been distributed to external financiers. The current division expands on this internal profit in the perspective of the earlier exposition - especially that of finance. Along with it (and building on $3 \mathrm{D}_{5}$ ) this division expands on the determinants of macroeconomic expenditure that result in the internal profit of enterprises.

This division starts by considering the rate of profit $(5 \S 1)$, moving to the mass of profit in the later sections.

Unless otherwise indicated, all equations in this division refer to the period $(\mathrm{t})$. 


\section{$5 \$ 1 \quad$ The rate of integral profit and the rate of internal profit}

This section presents the interconnection between the finance of production enterprises (Chapter 3 ) and their rate of profit. This is relevant for the enterprises' investment decisions as presented in $5 \S 5$.

1

The rate of integral profit (the rate of surplus-value on capital)

The production of capital being predicated on the monetary-value dimension and the commodification of labour-capacity $\left(\mathrm{ID}_{2}\right.$ and $\left.{ }_{1} \mathrm{D}_{3}\right), 1 \S 13^{-1} 1_{14}$ presented the rate of integral profit on capital $(\omega)$ as the core measure of the production of capital.

$$
\omega=\frac{\Pi}{\mathrm{K}}=\frac{\mathrm{mL} \mathrm{L}^{\alpha}-\mathrm{wL}}{\mathrm{K}}
$$

Much of its dynamic determinants were concretised in $2 \mathrm{D} 2$ and its synthesis in $2 \S 6$ (see also Figure 2.5). Prior to the exposition of money expansion $\left(2 \mathrm{D}_{4}\right)$ and of the finance of enterprises (Chapter 3 ), the latter determinants were only implicit in the rate of integral profit on capital $(\omega)$. This rate indeed applies to the totality: it is independent of how production capital is financed and independent of what part of surplus-value accrues to financiers including banks (Chapter 3).

The rate of internal profit of production enterprises

I now make explicit this earlier concretisation (Chapters 2-3) regarding the profit rate that will be called the 'rate of internal profit' of enterprises, which is their profit rate after the distribution of surplus-value to external financiers (banks, bondholders and holders of other loans). External finance and the calculation of profit over the internal (own) capital of enterprises affects the numerator and the denominator of (1.6).

- Let the share of 'external' finance (banks plus other financiers) in capital be $\varepsilon$ (epsilon). Hence the internal finance capital is $(1-\varepsilon) \mathrm{K}$.

- Let $i$ be the average rate of interest (the weighted average of the rates paid to banks and to other external financiers). Then the interest paid by production enterprises is $i \varepsilon \mathrm{K}$. This is the part of surplus-value that production enterprises share with external financiers.

Thus we have for the 'internal profit', $R$ (first introduced in $3 \S 1$; cf. Figure $3.2 b$ ): $\mathrm{R}=\Pi-i \varepsilon \mathrm{K}$

That is, surplus-value minus its share distributed to external financiers. ${ }^{1}$

The rate of internal profit on the internal capital is called $\rho$ (rho):

1 Recall that 'banking entities' generate surplus-value for their service of bookkeeping, and that these, for their part, are considered as production enterprises. However, their branch 


$$
\rho=\frac{\mathrm{R}}{\mathrm{K}-\varepsilon \mathrm{K}}=\frac{\mathrm{mL}^{\alpha}-\mathrm{wL}-i \varepsilon \mathrm{K}}{\mathrm{K}-\varepsilon \mathrm{K}}
$$

Dividing (5.2) by $\mathrm{K}$ we have:

$$
\rho=\frac{\left[\mathrm{mL}^{\alpha}-\mathrm{wL}\right] / \mathrm{K}-[i \varepsilon]}{1-\varepsilon}=\frac{\omega-i \varepsilon}{1-\varepsilon}
$$

- As long as $i<\rho($ or $i \varepsilon<\omega)$, external finance acts as an amplifier on $\rho$. Conversely $i>\rho$ pulls down $\rho$.

Thus $\varepsilon$ is a finance factor and $\rho$ takes account of this finance. ${ }^{2}$

We can interpret each of the equations presented above both microeconomically (then the subscript ' $i$ ' is used) and macroeconomically (properly: a semi-macroeconomic two sector account - one sector for production enterprises and the other for external financiers as including banks).

A corollary of this subsection is that 'the tendency to equalisation of average inter-sector rates of integral profit' (4\$2) takes the form of 'the tendency to equalisation of average inter-sector rates of internal profit'.

In sum, the internal capital measure $\rho$ is the 'concentration' of the determinants that were developed so far. Nevertheless, the rate of integral profit $\omega$ remains relevant for the total economy's production capital, and for the production capital of any one enterprise. The share of $i \varepsilon \mathrm{K}$ is 'merely' an important distributional component.

\section{$5 \S 2 \quad$ The realisation of surplus-value $(\Pi)$, and the internal profit $(R)$ as a distributional result}

$1 \quad$ Validation of surplus-value produced

$3_{5} \mathrm{D}_{5}(3 \S 10)$ presented the macroeconomic validation (realisation) of surplusvalue.

$$
\Pi_{\mathrm{t}} \triangleleft=[\mathrm{I}+\mathrm{Ck}+(\mathrm{CW}-\mathrm{W})]_{\mathrm{t}}
$$

and

$$
\Pi_{\mathrm{t}} \triangleleft=[\mathrm{I}+\mathrm{Ck}-\mathrm{Sw}]_{\mathrm{t}}
$$

of 'banks' regards purely their finance, for which these share in surplus-value (their part of $i \varepsilon \mathrm{K})-3 \S 1$.

2 Mainstream business accounting uses the term 'net profit after taxes'. Let us call this Rat ('at' for after taxes). Then it has for what is called the 'return on equity' (ROE): ROE = Rat / (K-عK). This is a consistent measure $\left(\rho_{\mathrm{at}}\right)$. It also adopts what is called the 'return on assets' (ROA): $\mathrm{ROA}=$ Rat $/ \mathrm{K}$. This of course measures what it does. Note though that the numerator (Rat) is dependent on how the enterprise is financed, whereas the denominator $(K)$ is independent of the way of finance. Our $\omega=\Pi / \mathrm{K}$ has each of the numerator and denominator independent of the finance. More significant is that in the conventional measures it is rather implicit that each of the internal profit $(\mathrm{R})$ and interest $(\varepsilon \mathrm{K})$ descend from surplus-value.

(See http://thismatter.com/money/stocks/valuation/profitability-ratios.htm for a brief outline of the ROE and rOA definitions.) 
(Ck denotes the consumption expenditure by capital owners, both the external and the internal financiers - the latter being the (quasi) shareholders. Sw denotes the saving out of wages. $)^{3}$ Recall the essential sequence of 'production of surplus-value' as predicated on the pre-validating finance by banks, of 'validation of surplus-value produced' and of the 'distribution of surplus-value' (3§10).

The internal profit as a result of production, validation and distribution

Substituting (3.10) in (5.1) we have, ex post, that is, after the distribution of $i \varepsilon \mathrm{K}$, the result of the internal profit:

$$
\mathrm{R}_{\mathrm{t}}=[\mathrm{I}+\mathrm{Ck}-\mathrm{Sw}]_{\mathrm{t}}-i \varepsilon \mathrm{K}_{\mathrm{t}}
$$

[validation-distribution mix] (5.4)

Hence, in contradistinction to (3.10) and (3.12), (5.4) is not a pure validation equation. Substituting (5.4) into (5.2) we have, after the validation of surplusvalue, for the rate of internal profit:

$$
\rho=\frac{\mathrm{R}}{\mathrm{K}-\varepsilon \mathrm{K}}=\frac{\mathrm{I}+\mathrm{Ck}-\mathrm{Sw}-i \varepsilon \mathrm{K}}{\mathrm{K}-\varepsilon \mathrm{K}} \quad \text { [validation-distribution mix] }
$$

The following sections of the current division expand on the determination of equation (5.4): consumption and saving (5§3), external finance and the rate of interest $(5 \S 4)$ and investment $(5 \S 5)$.

\section{$5 \S 3 \quad$ Determinants of saving by labour and consumption by capital owners}

This section briefly expands on the determination of $\mathrm{Ck}$ and $\mathrm{Sw}$ in equation (5.4). (The same applies for equation 3.12). Consumption and saving by labour and capital owners were introduced in $3 \S 10$. Here I briefly expand on these in connection with the phases of the business cycle broadly considered (the particularities of these phases are presented in $5 \mathrm{D}_{2}$ ).

\section{$1 \quad$ Saving by labour}

We have by definition that $S w \equiv s_{w}(w L)$. However, the savings ratio $s_{w}$ out of the wages income $\mathrm{wL}$ is not constant. When wages rise, the savings ratio tends to increase (and vice versa). The unemployed will dis-save as long as they can, and further survive on the savings of relatives and friends or perhaps saved funds of labour unions. Thus in all these cases the (cyclical) variation of unemployment tends to go along with a variation in savings.

3 In $3 \S_{2}$ it was indicated that the term 'dividends' is considered to include the 'quasi dividends' that flow from non-incorporated enterprises to their owners. 
The income of capital owners varies over the phases of the business cycle. Regarding (quasi) shareholders: when profits $(\mathrm{R})$ rise, more dividends tend to be distributed (and vice versa). Regarding external financiers: when banks and other financiers perceive an increase in risk and uncertainty, the rate of interest tends to increase (and vice versa). Therefore the income of capital owners varies over the business cycle. Nevertheless they tend to hold on to an autonomous constant standard of living and so expenditure (Ck). When their income exceeds their expenditure, they save, and when it falls short, they dis-save. ${ }^{4}$ Therefore their expenditure functions as an automatic stabiliser.

Thus, generally, in a recession the savings ratios tend to decline and in an upturn they tend to rise. (In 5 D2 this is set out more specifically for the various phases of the cycle.)

\section{$5 \$ 4 \quad$ External finance: the PVF, the RPVF and the rate of interest}

This section amplifies on the determination of $i \varepsilon \mathrm{K}$ in equation (5.4).

\section{Variations of the PVF and RPVF}

Recall from Chapter 3 the concept of the 'pre-validating finance' by banks $(\mathrm{PVF})$. An increase in economic growth requires an increasing PVF (and vice versa). To the extent that there are savings by labour and by capital owners, and a fortiori when these increase, production enterprises are unable to redeem the PVF whence we have a 'remaining PVF', abbreviated as R PVF (see the summary in Figure 3.14 of $3 \S 6-\mathrm{c})$. The $\triangle \mathrm{RPVF}$ varies with the PVF alongside the savings that are themselves dependent on the phase of the business cycle $(5 \S 3$ and amplified in $5 \mathrm{D} 2$ ).

The RPVF and the rate of interest

This subsection introduces some simplifications that serve to reduce the complication of the exposition of the business cycle in the next division.

Figure 3.14 also summarises the point that non-bank financiers may ex post substitute for the RPVF. In 5 D2 I will hardly emphasise this, and merely take

4 Behind this is in fact a Kalecki consumption function (Kalecki 1971 [1933], p. 1), which is similar to a Keynes one applied to capital owners separately. Kalecki has: $\mathrm{C}_{\mathrm{k}}=\mathrm{B}_{0}+\lambda \mathrm{P}$ (where $\mathrm{B}_{0}$ is an autonomous component and P stands for profits). He remarks 'where $\lambda$ is a small constant'. In what follows I neglect this 'small' profit-dependent component. Thus, as already indicated in $3 \S 10$, even if the capital owners' level of consumption is autonomous, some expost level of savings $(\mathrm{Sk})$ from the dividends and interest distributed $(\mathrm{PD})$ results: $\mathrm{PD} \equiv \mathrm{Ck}+\mathrm{Sk}$.

In case capital owners borrow from banks, this is (macroeconomically) not for consumption, but rather for their primary or secondary finance activities (Appendix $3 \mathrm{~A}, \S 3 \mathrm{~A}-2$ ). 
changes in the RPVF as an approximation for the external finance cost of enterprises (analogous to a change in $i \varepsilon \mathrm{K}-5 \S 1$ ). Hence in $5 \mathrm{D} 2$ the issuance of new shares is neglected (this means in effect that this issuance is taken as constant). Then we have as an approximation: $\Delta \mathrm{RPVF} \approx \Delta \varepsilon \mathrm{K}$. To the extent that an increase in the external finance ratio $\varepsilon$ implies a risk for external financiers, they will require a risk premium on the rate of interest (and vice versa). Then a $\Delta i$ moves along with a $\Delta \mathrm{RPVF}$ (hence we have for a $\Delta i \varepsilon \mathrm{K}$, a quantity effect $\Delta \varepsilon \mathrm{K}$ combined with a price effect $\Delta i$ in the same direction).

\section{$5 \$ 5 \quad$ Determinants of investment}

This section outlines the determinants of investment (I), the remaining component of profits equation (5.4).

Investment: preliminary conceptualisation

$\mathrm{K}$ being the total capital accumulated, investment is the addition to it: $\Delta \mathrm{K}_{\mathrm{t}}=\mathrm{I}_{\mathrm{t}} \quad$ [neglecting devaluation by scrapping beyond obsolescence] (5.6) $\Delta \mathrm{K}_{\mathrm{t}}^{*}=\mathrm{I}_{\mathrm{t}}-$ scrap $_{\mathrm{t}} \quad$ [including scrapping beyond obsolescence ${ }^{5} \quad$ (5.6a) Relative to consumption the determinants of investment are rather complex, and in outcome investment is far more volatile than consumption. Investment is mainly determined by two factors (each of which being the concentration of many determinants): the rate of internal profit $(\rho)$ in the previous period; and the rate of undesired overcapacity $(\varnothing)$ in the previous period.

$$
I_{t}=f\left(\rho_{t-1} ; \emptyset_{t-1}\right)
$$

[I being positively related with $\rho$ and negatively with $ø](5 \cdot 7)^{6}$

Investment and the rate of internal profit $(\rho)$

Next to the rate of integral profit $(\omega)$ the rate of internal profit $(\rho)$ is the 'concentration' of the determinants that were developed so far in this book. This concentration is also transmitted into the determination of investment. I especially refer to all the factors determining the process of production of capital $\left(1 D_{5}\right)$, including its management $(2 \S 2)$, and its conditions in the expansion of labour capacity $\left(2 \mathrm{D}_{3}\right)$, money expansion $\left({ }_{2} \mathrm{D}_{4}\right)$, finance $\left({ }_{3} \mathrm{D}_{2},{ }_{3} \mathrm{D}_{3}\right)$, the production validating macroeconomic expenditure $\left(3 \mathrm{D}_{4}\right)$, as well as the constellation

5 Equilibrium models do with (5.6). Equation (5.6a) makes explicit why accumulation of capital cannot be reduced to investment.

6 This equation deviates somewhat from equation (3.8) in $3 \$ 10$. First, the PVF condition is now implicit in $\rho$ via $i \varepsilon \mathrm{K}$. Second, the factor of desired production $\left(\mathrm{X}^{\mathrm{d}}\right)$ in $(3.8)$ (posited prior to the introduction of stratification in Ch. 4 ) is now specified via the overcapacity factor $ø$, as amplified below. 
of the stratification of enterprises $\left(4 \mathrm{D}_{1}, 4 \mathrm{D}_{3}\right)$. Thus the rate of internal profit is the capitalist system's key immanent measure for the movement of capital and so investment. ${ }^{7}$

I reemphasise that in this book's exposition - on this issue inspired by Kalecki - profits do not determine investment in the sense of financing investment - contrary to mainstream economics - but that investment is, via the validation of surplus-value produced ( $3 \$ 10)$, a main determinant of profit ('main', that is, next to $i \varepsilon \mathrm{K})$. Nevertheless this profit as a result determines the rate of profit $(\rho)$ as a result, which as a success indicator co-determines the investment in the next period. Thus the combination of equations 3.10 and 5.7, or 5.4 and $5 \cdot 7$ (including their time indices) is essential.

Note that, given the determination of $p$ (equation 5.2), the finance of investment is taken account of via the rate of interest $(i)$. The assertion behind it is that enterprises can always get credit from banks even if perhaps at a rate of interest that they consider exorbitant, as a result of which they might decline.

Investment and the rate of undesired overcapacity ( $ø)$

The rate of technical (over)capacity measures the current production in reference to the qua cost optimal production at the current capital assets $(\mathrm{K}) .^{8} \mathrm{I}$ make a distinction between desired overcapacity (o) and undesired overcapacity (ø). Individual enterprises may want to hold on to some degree of overcapacity (o), first, because they expect an increase in effective demand in the near future, and second, for market strategic reasons (regarding the market share or competitive price reactions)..$^{9}$ The rate of undesired overcapacity (ø) measures the overcapacity beyond its desired rate. ${ }^{10}$ From now on 'desired overcapacity'

The following point is not relevant for the business cycle but rather for the structural movement of the capitalist system. Even if the rate of internal profit is a key determinant of investment, 'the' rate of internal profit provides no absolute benchmark, as the appropriateness of the going average or modal rate of internal profit is customary and related to the broad stage of structural development. Relevant for the business cycle is the rate of internal profit in the going epoch, which stretches over a multiple of cycles.

8 This (over)capacity applies for plant and equipment as well as for the part of the labour capacity that cannot (or not easily) be varied. Any overproduction is considered to be a temporary factor to which enterprises can adapt fairly quickly in most sectors.

9 We saw in $4 \mathrm{D}_{3}$ that enterprises may produce at overcapacity either of their own free will for strategic reasons (the price-leader), or because the market circumstances enforce them to do so (those that are enforced to comply with the price-leader).

10 Any overcapacity has a negative effect on the current rate of profit via, mainly, the denominator K. For the desired overcapacity this negative effect is expected to be compensated in the future. 
will be indicated as such. For brevity 'overcapacity' always stands for 'undesired overcapacity' (ø).

We will see in $5 \mathrm{D} 2$ that this overcapacity $(\varnothing)$ is a crucial determinant for the course of the cyclical movement of the production and accumulation of capital. More precisely it bounds the investment as determined by the rate of internal profit. Even if at some juncture enterprises would consider the rate of internal profit $(\rho)$ 'high' or high enough to undertake profitable additional investment, it makes no sense to further increase the capacity when there is overcapacity, that is, beyond its desired rate. Note that the desired overcapacity also indicates the degree of the enterprises' 'optimism' about the future. ${ }^{11}$

\section{5§5-a Addendum: Steindl on investment}

Capacity and undesired overcapacity as a determinant of investment can also be found in Steindl (1976 [1952]). Steindl also has what he calls 'a factor of indebtedness' as affecting profits (cf. equation 5.5 above, and my approximation of $\Delta \mathrm{RPVF} \approx \Delta \varepsilon \mathrm{K}$ in $5 \S 4$ ). On Steindl see also Hein (2015), esp. sections 3-4, and the references he provides.

\section{5§6 A condensed macroeconomic sequence}

This section takes some of the previous threads together in terms of an utterly condensed economic sequence. It is difficult to present a macro process sequentially, because we in fact have microeconomic and macroeconomic circuits in which everything is a simultaneous movement. Nevertheless (a change in the level of) economic activity starts inevitably with production.

(o) A state of the economy results in a rate of internal profit $(\rho)$ at some rate of overcapacity (ø) - the latter might be zero. This result determines the next state and the sequences thereof. (See Figure 5.2, column 1.)

(1) The result determines the intended level of the new production $-\mathrm{mL}^{\alpha}$ being its core. The level of change is determined by PVF mediated investment for which the realised $\rho$ and $\varnothing$ are decisive. (Figure 5.2, column 2.)

(2a) Labour generates production $(\alpha)$ whereas its wages are output realising (sales of producers of consumer goods). Investment is capacity generating (production) as well as output realising (sales of the producers of means of production).

11 The distinction between the desired and the undesired overcapacity thus includes the factor that Keynes (1936) called 'animal spirits' (instincts of the enterprises' management about the future). 
(2b) The expenditures by enterprises and capital owners (their investment and consumption) minus the savings by labour realise profits (via the realisation of surplus-value). (Figure 5.2, column 3.)

(3) This results in a rate of internal profit $(\rho)$ at some rate of overcapacity (ø), which determines the next state and the sequences thereof (analogous to (o) above). (Figure 5.2, column 4.)

FIGURE 5.2 Condensed macroeconomic sequence of production and profit determination

(1)

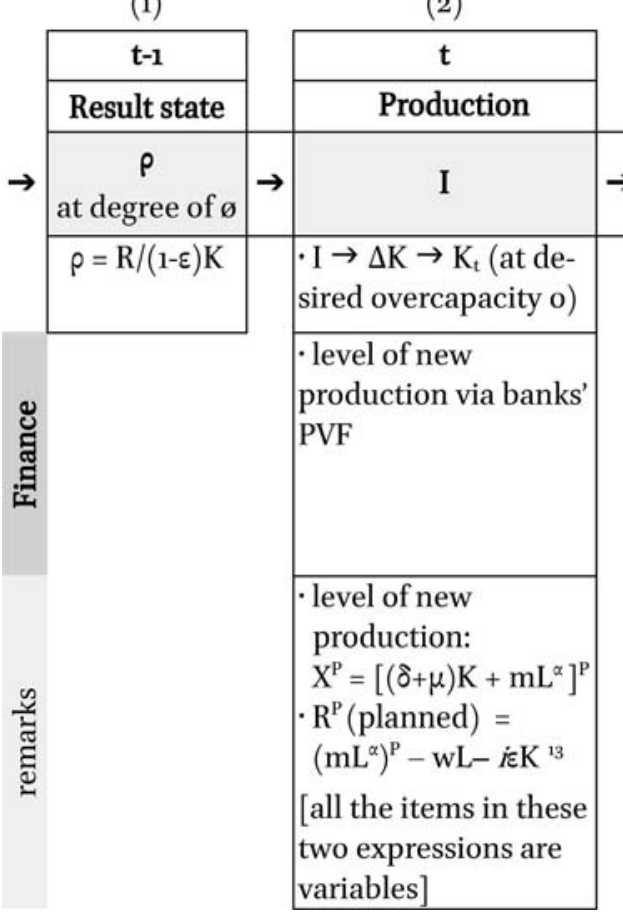

(3)

\begin{tabular}{|c|c|}
\hline (3) & (4) \\
\hline $\mathbf{t}$ & $t$ \\
\hline Validation \& distribution & Result state \\
\hline $\begin{array}{c}\Pi \varangle=\mathrm{I}+\mathrm{Ck}-\mathrm{Sw} \\
\mathrm{R}=\Pi-\dot{k} \mathrm{~K}\end{array}$ & $\rightarrow \quad \begin{array}{c}P \\
\text { at degree of } ø\end{array}$ \\
\hline $\begin{array}{l}\mathrm{I} \text { is determined and } \mathrm{Ck} \text { is } \\
\text { stable }\end{array}$ & $\rho=R /(1-\varepsilon) K$ \\
\hline
\end{tabular}

- Sw and Sk:

determination of new

external finance factor $\varepsilon$ $(\text { RPVF })^{12}$

[Sw, Sk and $\varepsilon$ are variables]

- validation: ø may

deviate from the desired

overcapacity on which

investment was based;

- may in part take the

form of $\Delta$ inventories

5§6-a Addendum: Theories of the business cycle

Until the 196 os the business cycle was hardly theorised by mainstream neoclassical economists, presumably because it was hard to fit within their equilibrium framework. By that time Friedman and his collaborators took up the matter, followed by Lucas towards the end of the 1970s. Prior to it, business cycles had been mainly studied and theorised by the non-mainstream heterodox strands in economics/political economy, Marx being the first business cycle theorist (see Appendix 5B). As indicated in the General Introduction, it is generally beyond the scope of this book to review the literature (references are mainly 
restricted to tributes and acknowledgements). For a series of brief overviews regarding strands of business cycle theories, I refer to articles in An Encyclopedia of Macroeconomics (editors Snowdon and Vane 2002) and the literature discussed in those. Mainstream strands: Monetarist approach (Hammond 2002); New Classical approach (Snowdon and Vane 2002b); Political Business Cycle approach (Frey and Benz 2002); Real Business Cycle approach (Ryan 2002). Heterodox strands: Austrian approach (Garrison 2002); Keynesian approach (Trigg 2002); Marxian approach (Reuten 2002b).

5§6-b Amplification. Empirical business cycle indicator USA 1950-2015 As preliminary to the next division, Graph 5.3 shows the change of GDP and the recession periods in the USA from the second half of the twentieth century onwards.

GRAPH 5.3 Change of GDP and recessions in the USA 1950-2015

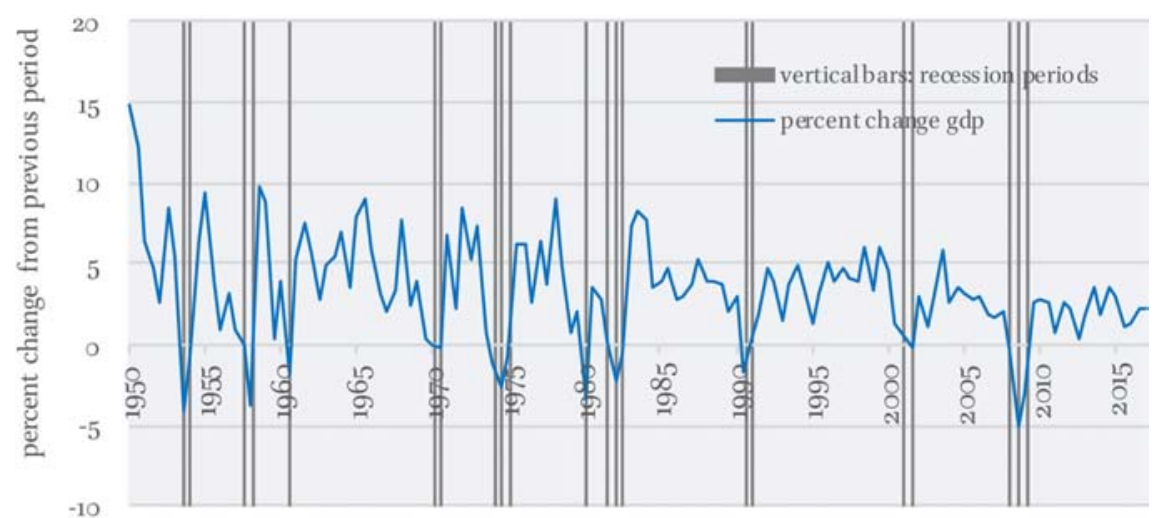

Line: Real GDP, \% change from preceding period, semi-annual, seasonally adjusted annual rate. Vertical bars: NBER based recession indicators from the period following the peak through the trough, semi-annual.

DATA SOURCE: FRED economic data (Federal Reserve Bank of St. Louis) ${ }^{12}$

12 https://fred.stlouisfed.org/. G DP updated 21 December 2017; NBER index updated 3January 2018 (each accessed 11 January 2018). 


\section{Division 2. The cyclical over-accumulation and destruction of capital}

Business cycles

With this division we reach the most concrete level of the exposition of the capitalist economy in this book. Although the movement of capital is necessarily cyclical in some way, this should be understood as a necessary up and down movement, a movement of accelerating expansion and next a stagnation and contraction. In that sense the cycles of movement are regular. This regularity does not apply to the length of cycles (the time between the top of one cycle and the top of the next) or the amplitude of cycles (the difference between the accumulation level at the top of a cycle and its trough). In the last sense this Division 2 definitely reaches contingency. In the first sense, however, the cyclical movement of capital is a concrete synthesis of all the necessary moments that were presented so far. The fact that the particular exposition in this division will not explicitly touch on each one of the moments presented in Chapters 1-4 is a matter of self-imposed restriction in terms of space (i.e. text). Division 1 prepared the floor for the moments on which this synthesis will explicitly touch.

Those readers who are accustomed to accounts of the business cycle just in terms of models should be warned that the current division - as a 'moment' rather presents the framework for a model.

\section{$5 \$ 7 \quad$ The phase-wise stratified cyclical movement of capital: preliminaries}

The determinants of the capitalist economy that were presented so far seem to sustain the continuous accumulation of capital via expanding production (Chapters 1-4). In fact, as we will see in $5 \S 8$, these determinants sustain this accumulation so much that they recurrently generate an over-accumulation of capital that leads - for a considerable time at least - to apparently system perverse dis-sustaining reactions. We will see that the 'logic' of accumulation so turns in its opposite of destruction of capital along with the expulsion of labour, that is, of the generator of surplus-value. The euphemism for it is economic 'contraction'. Then, for the reproduction of the capitalist system, there should be system-immanent forces that lead from this contraction to renewed expansion (presented in $5 \S 9$ ). Together these are called the cyclical movement of capital.

Section $5 \$ 6$ presented a condensed macroeconomic sequence of the production, finance and accumulation of capital. In the following sections, the cyclical movement of capital is presented as one where such sequences move phase-wise in the same direction: expansionary or contracting. Figure 5.4 shows 
a stylised curvature of this cyclical movement, ordered in six phases that I will clarify in the next two sections.

FIGURE 5.4 Stylised shape of one business cycle (growth of production in 6 phases)

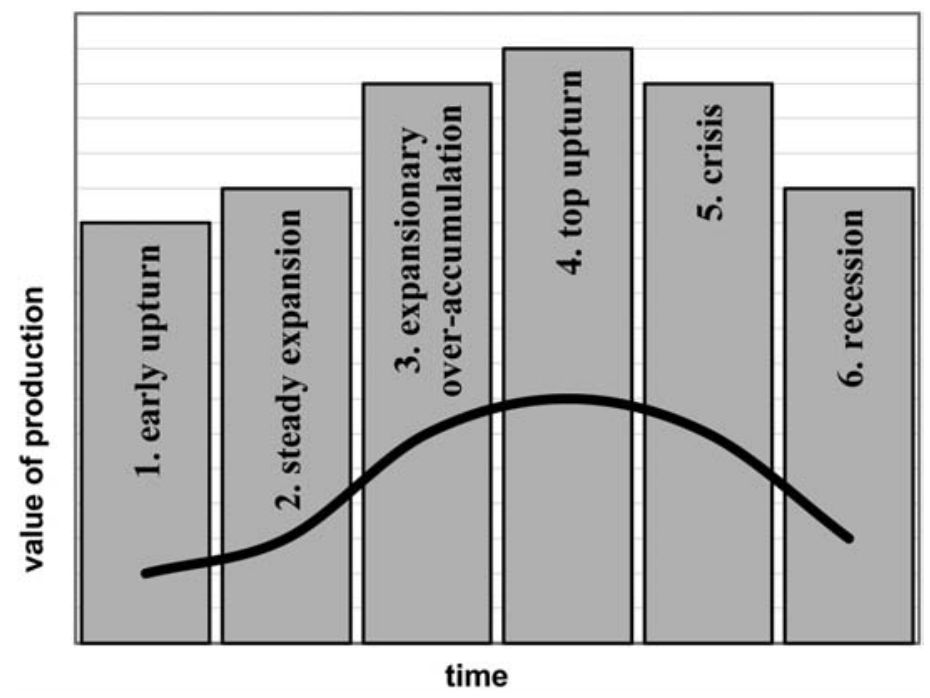

Note: Although the duration of each phase has been put to unity, the duration of the phases varies considerably in practice. Amplitudes (the value difference between trough and top) also vary considerably between cycles.

One major systematising framework for the exposition of the cyclical movement will be the stratification of capital (Chapter 4). On the one hand, the stratification will now be considered in macroeconomic perspective. On the other hand, it will be disentangled as the phase-wise form of the movement of capital. In adopting this framework the focus is on the competitive dynamic sectors of the economy within a constellation of marginal inflation (cf. $\left.4 \mathrm{D}_{3}\right)$. However, because the current exposition integrates all stratifications into one macroeconomic stratification, the stagnant sectors (cf. $4 \mathrm{D}_{4}$ ) are part of it.

Following on from Chapter 4, Figure 5.5 below could be interpreted as the movement through time of one random microeconomic sector (with plant addition at the top and scrapping at the bottom). However, in the remainder of the current division it is interpreted as a macroeconomic constellation. In what follows the regular scrapping (below the fat line at the bottom) will be neglected. 
FIGURE 5.5 Phase-wise macroeconomic stratification of capital

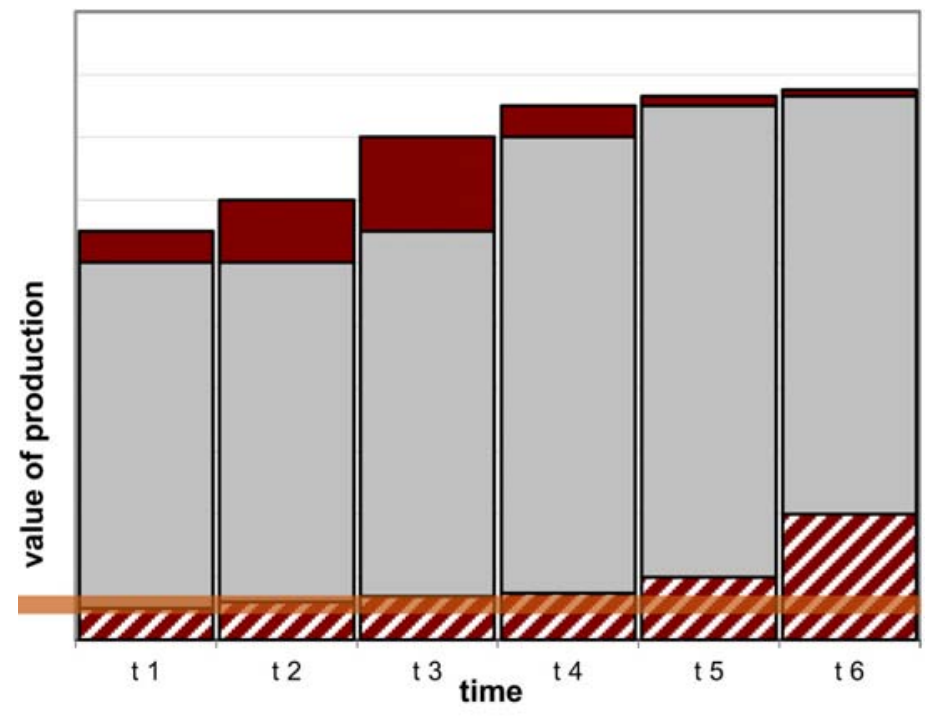

addition of plants $\square$ new bottom of stratification $\quad \square$ scrapping of plants

\section{$5 \$ 8 \quad$ Cyclical movement (1): from expansion to stagnation}

(In reading the text below the reader may want to consult the summaries in Figures 5.6 and 5.7 (on pp. 262-63). Expanding on the latter figure, all cyclical phases are outlined in some more detail in Explication $5 \S 9$-b, to which the reader may turn selectively as required. Note that especially Figure 5.7 is to serve those readers that require an overview of the details.)

The early and the steady expansion (phases 1 and 2)

In the first two phases of the expansion (the early upturn and the steady expansion) we have a negligible overcapacity and along with it an internal profit rate determined, increasing investment $(5 \S 5) \cdot{ }^{13}$ The result is rising profits $(\mathrm{R})$ and a rise in the rate of internal profit ( $\rho)$. After the hesitating early upturn phase (phase 1), actors perceive the second phase as one of 'back to normality', which generates a climate of optimism. Indeed, considering all the phases of the cycle, this second phase of steady expansion is one of modal ('normal') circumstances (see the list in the second column of Figure 5.7).

13 In $5 \S 9$ we will see how the early expansion starts from an increased rate of profit as an outcome of the recession (i.e. the previous phase). 

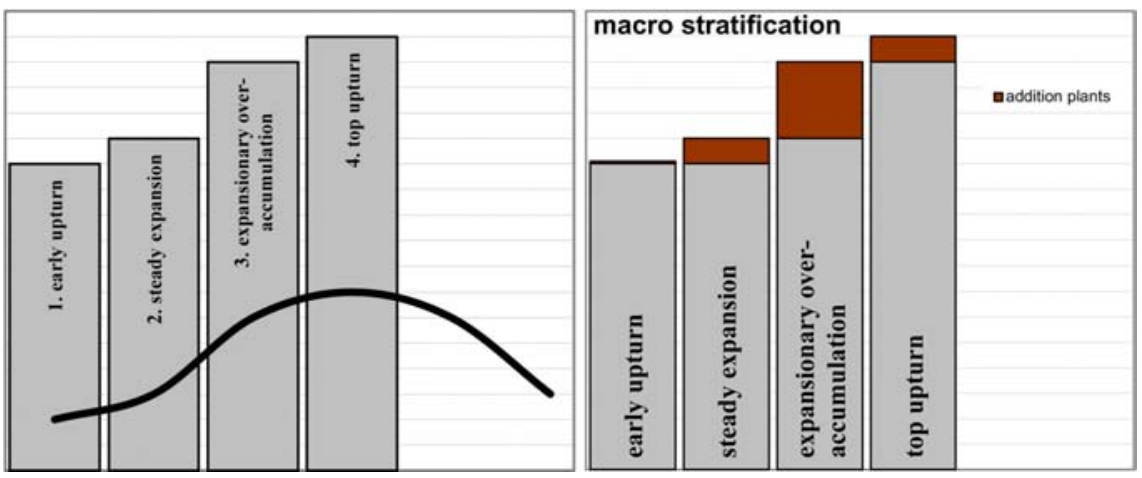

\section{$B$} Expansionary over-accumulation (phase 3)

The main conditions for the crisis and downturn are laid in the third phase of the expansion. Actors generally perceive this phase as one of prosperity, which regarding incomes and employment it indeed is. Recall from $5 \S 2$ that

$$
\rho=\frac{\mathrm{R}}{\mathrm{K}-\varepsilon \mathrm{K}}=\frac{[\mathrm{I}+\mathrm{Ck}-\mathrm{Sw}]-i \varepsilon \mathrm{K}}{\mathrm{K}-\varepsilon \mathrm{K}}
$$

1. The rising profits $(R)$ and profit rate $(\rho)$ and the slim overcapacity in the previous phase engender a generalised euphoric investment. Enterprises are keen not to miss the opportunities. Overall the sector stratifications get extended boosts. By itself this generates another investment-determined boost in profits (R). However, the (inherently uncoordinated) broad increase in investment and hence capital accumulated $(\mathrm{K})$ - also generates vast overcapacity (ø). Taking these two issues in isolation, we have, regarding the rate of internal profit $(\rho)$, the profits increase effect from investment expenditure, dominating over the capital increase effect, whence $\rho$ increases.

2. However, the profits $(\mathrm{R})$ are mitigated by increased savings (hence pressure on effective demand). Because the expansion goes along with increased employment as well as increased wages, the savings from the part of labour rise $\left(\mathrm{Sw}\right.$ - recall that this is mediated by an increasing savings ratio $\left.\mathrm{s}_{\mathrm{w}}\right)$. Recall that the consumption expenditure by capital owners is roughly constant (nevertheless their savings, Sk, which increase due to an increased distribution of profits, affect the RPVF - point 3 below).

3. The profits $(\mathrm{R})$ are further mitigated due to finance. Because of the expansion, not only is the pre-validating finance by banks (PVF) boosted, but, more important, the increased savings mean that a larger part of it cannot be redeemed $(\triangle \mathrm{RPVF})$. Thus we have an increasing $\Delta \mathrm{RPVF} \approx \Delta \varepsilon \mathrm{K}$. Because of the increasing risk, the rate of interest increases $(i)$. This means (cf. $5 \S 4)$ that the leverage effect of external finance is pressed down (and perhaps already starts becoming negative). 
The net effect $(1-3)$ on profits and the rate of internal profit $(\rho)$ is an empirical matter. Say that, in comparison with the previous phase, $\rho$ is roughly constant. Perhaps it declines or increases. For the further course of the cyclical movement this is not particular important, as we will see below.

Generally this third phase turns the steady accumulation of phase 2 into over-accumulation of capital (nevertheless this fits the 'logic' of accumulation $\left.-2 \mathrm{D}_{1}\right) \cdot{ }^{14}$

C The top of expansion and turning point (phase 4)

Most important for the next phase - the top phase of the expansion - is the overcapacity that has been built up. ${ }^{15}$ Given the determinants of investment (the rate of internal profit and undesired overcapacity) the enterprises weigh these factors. Faced with undesired overcapacity they perceive that extra investment makes no sense $(5 \S 5) \cdot{ }^{16}$ Hence enterprises will generally cut back on investment (some investment may still go on, first, because of investment plans in the pipeline, and second, because of a number of enterprises remaining optimistic). This decrease in investment implies that the investment expenditure effect on profits now dominates negatively, whence the rate of internal profit definitively declines, and sharply so. Note that whereas the growth of the PVF and RPVF decline because of the declined investment, the risk for banks is still increasing whence the interest rate further dampens the profits (R).

Because the growth of production goes on (though at a slackened rate) employment increases and hence there is a further upward pressure on the wage rate, with the same effects as indicated above (B-2) for savings - now further reinforced.

On the basis of the composition of forces it is not evident what action enterprises should take. For small and medium-sized enterprises there is no easy way out. For large to very large enterprises, however, this tends to be differ-

14 The over-accumulation of capital is measured, ex post, by the rate of undesired overcapacity (ø); see further Explication $5 \S 9$-b.

15 Overcapacity is openly observable in cases such as real estate ('for rent'). The previous construction of buildings boosted employment and profits. Similar phenomena occur, less openly observable, behind the gates of production enterprises - less openly, that is, until plants are closed down.

16 This is so except when an individual enterprise could make a great innovative leap $\left(4 \mathrm{D}_{3}\right)-$ great, that is, on top of the advances already implemented in the previous phase on a broad scale. 
ent. ${ }^{17}$ Their size and the fact that these are often composed of several plants put them in a position to undertake a cost-cutting restructuring (reorganisation) of their enterprise. Along with it they will, selectively, slow-down their replacement investment as well as their hiring of labour-capacity (hence for those enterprises/plants we have a slow to negative rate of growth for each). Although from their perspective this makes sense, the macroeconomic effect of these actions takes off the remaining growth and puts an end to the general expansion.

\section{A note on the duration of phases}

I end this section with a note on the calendar time of the various phases. The duration of each of the phases is an empirical matter. The duration of a phase might, for example, be half a year, but also three years or longer. Empirically it appears that the length of a complete cycle takes between 6 and (rarely) 12 years. This matter is relevant for the characterisations of each phase (see also Figure 5.7). For example, should the phase of over-accumulation (the third phase) be an extended one with perhaps a gradually developing overaccumulation and overcapacity, then the rate of profit $(\rho)$ will tend to move to declining during that phase, perhaps halfway or towards the end.

5§8-a Explication. Summary of the phases of the cyclical movement of capital

Figure 5.6 outlines a simple summary of the phases of the movement of capital (taking together the four expansion phases and the two contraction phases). Figure 5.7 is a more detailed summary. At this point only the expansion is relevant (the reader can turn to the contraction part after reading the next section).

17 The relative importance of 'large' enterprises is contingent on a particular economy. Just as an example, for the Netherlands in 2010 'large enterprises' (above 1oo workers) made up almost $1 \%$ of the total number of enterprises with just over $6 \circ \%$ of the total employment. (Amongst these the 'very large enterprises' ( $>5$ oo workers) made up $0.2 \%$ of the number of enterprises with $44 \%$ of the total employment.) (Source: Netherlands Central Bureau of Statistics, 'Statline', accessed 12 March 2012.) 
FIGURE 5.6 Simple summary of the cyclical movement: expansion and contraction

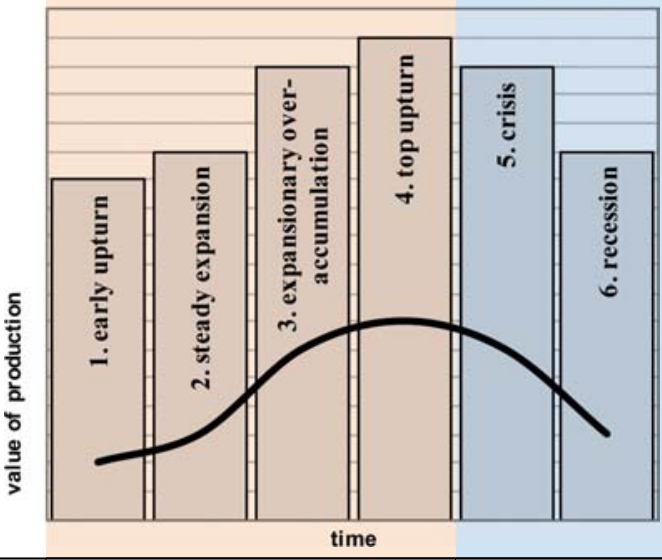

\begin{tabular}{|c|c|c|}
\hline & EXPANSION (ph. 1-4) & CONTRACTION (ph. 5-6) \\
\hline $\begin{array}{l}\text { Production and Investment } \\
\text { Investment }(\Delta \mathrm{K}) \\
\text { Production and employment } \\
\text { Wage rate } \\
\text { Unemployment rate }(\mathrm{u})^{*}\end{array}$ & $\begin{array}{c}\text { from } \uparrow \text { via } \uparrow \uparrow \text { to } \downarrow \\
\uparrow \\
\uparrow \\
\downarrow\end{array}$ & $\begin{array}{l}\downarrow \\
\downarrow \\
\downarrow \\
\uparrow\end{array}$ \\
\hline $\begin{array}{l}\text { Finance } \\
\text { PVF from banks } \\
\text { savings effect on RPVF } \\
\text { resulting RPVF and } \varepsilon \mathrm{K} \\
\text { resulting } i \varepsilon \mathrm{K}\end{array}$ & $\begin{array}{c}\uparrow \\
\mathrm{Sw} \uparrow ; \mathrm{Sk} \uparrow \text { (each increasingly) } \\
\uparrow \\
\uparrow\end{array}$ & $\begin{array}{c}\downarrow \\
\mathrm{Sw} \downarrow ; \mathrm{Sk} \downarrow \\
\downarrow \\
\downarrow\end{array}$ \\
\hline $\begin{array}{l}\text { Expenditure } \\
\text { Expenditure }(\mathrm{I}+\mathrm{Ck}-\mathrm{Sw}) \\
\text { Total expenditure }\end{array}$ & $\begin{array}{c}\mathrm{I} \uparrow ; \mathrm{Ck} \text { const.; } \mathrm{Sw} \uparrow \\
\uparrow\end{array}$ & 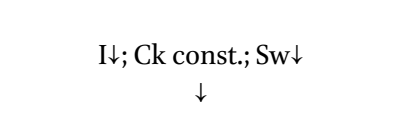 \\
\hline $\begin{array}{l}\text { Capital and capacity } \\
\text { Overcapacity }(\varnothing) \\
\text { Capital (K) }\end{array}$ & $\begin{array}{c}\text { from negligible to } \uparrow \uparrow \\
\uparrow \uparrow\end{array}$ & $\begin{array}{c}\text { capital destruction (to } \varnothing=0 \text { ) } \\
\downarrow\end{array}$ \\
\hline $\begin{array}{l}\text { Results } \\
\text { Profit }(\mathrm{R}=[\mathrm{I}+\mathrm{Ck}-\mathrm{Sw}]-i \varepsilon \mathrm{K}) \\
\text { rate of profit }(\rho=\mathrm{R} / \mathrm{K}-\varepsilon \mathrm{K})\end{array}$ & $\begin{array}{c}\uparrow(\text { expenditure dominates })^{\dagger} \\
\text { from } \uparrow \text { to } \downarrow\end{array}$ & $\begin{array}{c}\downarrow \text { (expenditure dominates) } \\
\text { from } \downarrow \text { to } \uparrow(K \text { effects dominate })\end{array}$ \\
\hline
\end{tabular}

* Ceteris paribus the labour population growth.

$\dagger$ Profit declines at top of expansion. 
FIGURE 5.7 Stylised summary of the cyclical movement of capital: core macroeconomic variables (amplified in 5\$9-b)

\begin{tabular}{|c|c|c|c|c|c|}
\hline early upturn & steady expansion & $\begin{array}{c}\text { over- } \\
\text { accumulation }\end{array}$ & top upturn & crisis & recession \\
\hline hesitating growth & steady growth & accelerating growth & decreasing growth & sudden zero growth & zero to neg. growth \\
\hline $\begin{array}{c}\mathrm{I} \uparrow ; \mathrm{K} \uparrow \rightarrow \mathrm{L} \uparrow, \mathrm{Y} \uparrow \\
\text { [hesitating] }\end{array}$ & $\begin{array}{c}\mathrm{I} \uparrow ; \mathrm{K} \uparrow \rightarrow \mathrm{L} \uparrow, \mathrm{Y} \uparrow \\
{[\text { steady] }}\end{array}$ & $\begin{array}{c}\mathrm{I} \uparrow ; \mathrm{K} \uparrow \rightarrow \mathrm{L} \uparrow, \mathrm{Y} \uparrow \\
\text { [accelerating] }\end{array}$ & $\begin{array}{c}\mathrm{I} \downarrow ; \mathrm{K} \uparrow \rightarrow \mathrm{L} \uparrow, \mathrm{Y} \uparrow \\
\text { [damping] }\end{array}$ & $\begin{array}{c}\mathrm{I} \downarrow ; \mathrm{K} \downarrow \rightarrow \mathrm{L} \downarrow, \mathrm{Y} \downarrow \\
{[\text { fast }]}\end{array}$ & $\begin{array}{c}\text { Iconst; } \mathrm{K} \downarrow \rightarrow \mathrm{L} \downarrow, \mathrm{Y} \downarrow \\
\text { [rickety] }\end{array}$ \\
\hline \multicolumn{6}{|c|}{ recall from $5 \S 5$ that investment ( $\mathrm{I}$ above) is determined by $\rho$ and $ø$ in the previous phase (see below) } \\
\hline $\begin{array}{c}\text { u const. } \\
\text { w const., } \alpha \uparrow, \mathrm{e} \uparrow\end{array}$ & $\begin{array}{r}\mathrm{u} \downarrow \text { (steady) } \\
\mathrm{w} \uparrow, \alpha \uparrow, \mathrm{e} \uparrow\end{array}$ & $\begin{array}{c}\mathrm{u} \downarrow \text { (accelerating) } \\
\mathrm{w} \uparrow, \alpha \downarrow, \mathrm{e} \downarrow\end{array}$ & $\begin{array}{c}\mathrm{u} \downarrow \text { (damping) } \\
\mathrm{w} \uparrow, \alpha \downarrow, \mathrm{e} \downarrow\end{array}$ & $\begin{array}{c}\mathrm{u} \uparrow \text { (hesitating) } \\
\mathrm{w} \downarrow, \alpha \uparrow, \mathrm{e} \uparrow\end{array}$ & $\begin{array}{c}\mathrm{u} \uparrow \text { (fast accelerating) } \\
\mathrm{w} \downarrow, \alpha \uparrow, \mathrm{e} \uparrow\end{array}$ \\
\hline \multicolumn{6}{|c|}{$\begin{array}{l}\text { stylised movement of 'macro' stratification } \\
\text { cation indexes the capital accumulated and the production in each phase }\end{array}$} \\
\hline & & (I overshooting) & $\sum n+5$ & $\sum \mathrm{n}+5$ & $\sum n+5$ \\
\hline & & $\sum n+4$ & running I plans \& & & \\
\hline & & plant addition & remaining optimism & & \\
\hline thin addition plants & $\sum \mathrm{n}+1$ addition plants & & & & \\
\hline$\sigma \approx$ const. & $\theta \approx$ const. & 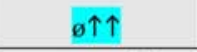 & $6 \uparrow$ & $\emptyset \downarrow$ & $\emptyset \downarrow$ \\
\hline I effect/R $\uparrow$ & I effect: $\mathrm{R} \uparrow$ & I effect: $\mathrm{R} \uparrow \uparrow$ & I effect: $R \downarrow \downarrow$ & I effect: $R \downarrow$ & I effect: R const. \\
\hline Sk and $S w \approx$ const. & $\mathrm{Sk} \uparrow ; \mathrm{Sw} \approx$ const. & $\mathrm{Sk} \uparrow ; \mathrm{Sw} \uparrow$ & Sk $\downarrow ; S w \uparrow$ & $\mathrm{Sk} \approx$ const; $\mathrm{Sw} \downarrow$. & Sk $\approx$ const; Sw $\downarrow$ \\
\hline Sw effect: $\mathrm{R} \approx$ const. & Sw effect: $\mathrm{R} \approx$ const. & Sw effect: R $\downarrow$ & Sw effect: $\mathrm{R} \downarrow$ & 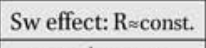 & Sw effect: $\mathrm{R} \uparrow$ \\
\hline RPVF $\approx$ const. & RPVF $\uparrow$ modest & RPVF $\uparrow \uparrow$ steep & RPVF $\uparrow$ modest & RPVF $\downarrow$ modest & RPVF $\downarrow$ strongly \\
\hline RPVF-Iever: positive & RPVF-lever: positive & RPVF-lever: down & RPVF-lever: down & RPVF-lever: negative & RPVF-lever: to pos. \\
\hline $\mathrm{K} \uparrow ; \mathrm{R}^{\prime}>\mathrm{K}^{\prime}$ & $\mathrm{K} \uparrow ; \mathrm{R}^{\prime}>\mathrm{K}^{\prime}$ & $\mathrm{K} \uparrow ; \mathrm{R}^{\prime} \approx \mathrm{K}^{\prime} ?$ & $\mathrm{~K} \uparrow ; \mathrm{R}^{\prime}<\mathrm{K}^{\prime}$ & $K \downarrow ; R^{\prime} \approx K^{\prime}<0$ & $\mathrm{~K} \downarrow ; \mathrm{R}^{\prime}>\mathrm{K}^{\prime}<0$ \\
\hline \multirow[t]{3}{*}{$p \uparrow$ modest } & $p \uparrow$ & $p \uparrow$ or $\approx$ const.? & $\rho \downarrow$ heavy & $p=$ const. & $p \uparrow$ \\
\hline & & & & & serapping plants \\
\hline & & & & & Dhystain and devalue \\
\hline$\sum 2$ & $\sum 2$ & $\sum 2$ & $\sum 2$ & $\sum \mathrm{h}+1$ & ating destructim \\
\hline$\sum 1$ & $\sum 1$ & $\sum 1$ & $\sum 1$ & 2hil & \\
\hline
\end{tabular}

- Remarks drawn in the stratification apply to the average of the full range of stratification.

- Changes $(\uparrow \downarrow><)$ or non-changes (constant) are in reference to the previous phase.

$\cdot \mathrm{x}^{\prime}=$ rate of growth of $\mathrm{x}$.

- The summation sign $\sum$ sums the micro sector stratifications (Chapter 4 ) to the macro level.

- The figure does not show continuous obsolescence and the replacement investment for it (Chapter 4).

- The figure does not show that in the crisis and recession a moderate (replacement) investment goes on.

- The figure abstracts from any 'normal' bad management failures over the cycle.

\begin{tabular}{|l|l|l|l|l|l|}
\hline$\alpha$ & productive power of labour & $\curvearrowleft$ & overcapacity, undesired (rate) & Sk & savings: capital owners \\
\hline e & rate of surplus-value $(\Pi /$ wL.) & PVF & pre-validating finance & Sw & savings: wages \\
\hline I & investment & RPVF & remaining PVF & u & unemployment rate \\
\hline K & capital (assets $\mid)$ & R & internal profit & w & wage rate \\
\hline L & labour employed & P & rate of internal profit & Y & macroeconomic income \\
\hline
\end{tabular}




\section{5§9 Cyclical movement (2): from stagnation to contraction and renewed expansion}

The interconnection of all the determinants of the capitalist system means that it can cope very well with economic growth - and hitherto most of the time indeed generates growth. However, the system can hardly cope with declining growth, and even less with shrinking activity (negative growth or decline). For these cases the system-immanent reactions are rather perverse, over-reactive and problem-aggravating.
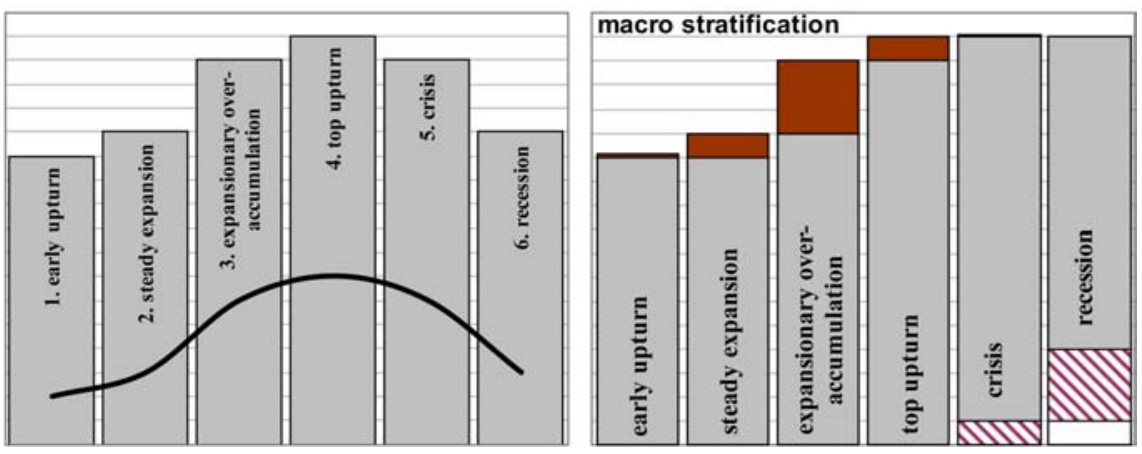

$A$ Economic crisis, or early recession (phase 5)

A-1 Spiralling down

We saw in $5 \S 8$ that at the top of the upturn, the reaction to a declining rate of profit by, initially, large enterprises, is a restructuring and alongside this a selective slowing down of investment increase and cuts in their hiring of labour-capacity. This gives rise to a general, effective demand generated, negative spiral in employment, investment and profits. Once this negative spiral is underway it is hard to stop. Once the economy moves into a (early) recession, lack of investment is not the sole problem; there is also a lack of effective demand in general. Further, although the PVF declines, the required interest on the RPVF built up earlier turns into a deleverage and so further squeezes internal profits.

In this phase the large enterprises continue their restructuring course of action from phase 4, and also close down plants. Small and medium-sized enterprises that already operated at a loss go bankrupt. The others do their utmost to cut on costs. Because of the physical destruction and/or devaluation of capital along with it $(\mathrm{K} \downarrow)$, the rate of profit may not further decline on top of the earlier sharp downfall.

How long this phase lasts, and how deep it cuts, much depends on the 
suddenness and length of the preceding top of expansion phase. A brief and sudden top phase tends to bring forth a steep crisis (or early recession).

A-2 Crisis and failure of banks

The early recession phase may but need not be associated with a banking crisis, including failure of banks. When accompanied by a banking crisis, then this phase cuts deep and tends to be of extended duration. The term 'crisis' is most appropriate for the combination of an 'early recession' and a banking crisis. ${ }^{18}$ We know from Chapters 2 and 3 that banks are essential to the capitalist system. Therefore the term crisis for the combination is appropriate, as a banking crisis is not only a crisis for banks, but indeed a crisis of the system.

In the recession phase the spiralling down (A-1 above) goes on. At the same time, however, this phase prepares the conditions for a new take-off. The remainder of this section primarily focuses on these conditions (B-1 to B-6) that result, as we will see, in a restoration of the rate of profit $(\rho)$.

B-1

Restructuring of capital: annihilation of capital accumulated

The main characteristic of the recession is 'restructuring of capital' much reinforced from its moderate start in the previous phase. In brief this involves reinforced internal reorganisations, bankruptcies, take-overs and mergers - for the latter two we so have a cyclical centralisation of capital (in contradistinction to a structural centralisation $-4 \mathrm{D}_{5}$ ). With it, and on top of the bankruptcies, the least efficient plants are closed down. Together these undo most of the overcapacity built up in the expansion phase. ${ }^{19}$ In sum we so have a violent cyclical destruction and so cyclical devaluation of capital. Hence part of the capital produced and accumulated in the previous phases of the cycle is annihilated $\left(\mathrm{K}^{\prime}<0\right)$. Thus the apparently insurmountable problems that came to expression at the end of the expansion $(5 \S 8)$ are 'resolved' by in part annihilating the expansion.

However, with it, the applied natural resources are destroyed - those that are accounted for in the MVD as well as those that are not (1§14, heading 2$)$. This so affects the, at least eventual, system requirement for a symbiotic metabolism of human beings with nature $(1 \S 9)$. More directly grinding, the destruction of

18 Before 1940, about one third of the cyclical tops ended with some form of banking crisis. The more scarce banking crises afterwards are related to state regulation (see Chapter 10).

19 'Most' of the overcapacity is done away with. Large corporations with sufficient reserves can often survive with overcapacity, perhaps assisted by banks. 
productive activity and productive capacity destroys employment of labour. The resultant misery is concentrated in those expelled into unemployment. Predominantly these, and their children, are sacrificed for the process of 'creation and destruction'. (Even if along this Sisyphean process the average real income per head may increase, the heads are not equal and especially the unemployed are 'hors catégorie' in this respect.)

The following factors are the 'by-products' of this restructuring assisting a new expansion.

B-2 Survival on savings and a declining RPVF

Due to the restructuring of capital, workers are laid off. Thus whereas many enterprises and financiers lose part of their capital (even if the corporate form of the enterprise mitigates risks $-2 \S 12$ and $3 \S 5$ ), many workers lose their means of subsistence. Often workers can, for some time at least, survive by drawing on previous savings (their own, that of relatives and friends, or of means collected by labour unions, for example). These dis-savings press down the RPVF. This also applies for capital owners who, with decreased or zero profits distributed, maintain their standard of living from their previous savings. From the part of the employed workers, savings are further pressed down due to wage decreases that result from the generalised unemployment.

B-3 Losses of banks along with rebuilding the structure of finance capital Due to restructuring of capital, and especially bankruptcies, banks too have to take finance capital losses. ${ }^{20}$ On the other hand, these also rebuild the structure of their balance sheet as presumably dubious assets disappear from the assets side.

Further, starting from the top of the upturn and continuing throughout the recession, banks take a breath from a too spurious increase of the PVF, and especially of the RPVF, in the phase of over-accumulation. ${ }^{21}$ This breath also rebuilds the structure of their balance sheet.

20 Even if banks may have reserves from risk premiums built up in the expansion, this still shortens their balance sheet.

21 Jakab and Kumhof observe that 'especially during the boom periods of financial cycles when all banks simultaneously decide to lend more, [this] is [the result of] their own assessment of the implications of new lending for their profitability and solvency.' However, 'an individual bank that considers whether to deviate significantly from the behaviour of its competitors' is faced with the dilemma of 'increased credit risk when lending too fast to marginal borrowers' and of a diminution of its clients when 'too many of them are lost to competitors' (2015, p. 5). 
B-4 Compliance of labour: disciplining by the recession

Along with the restructuring of capital, the rate of internal profit for the remaining enterprises is further pushed up because the unemployment affects the compliance, and so the power of labour in production - that is, of those that remain employed. Recall from $2 \mathrm{D}_{2}$ and $3 \mathrm{D} 6$ that the compliance of labour is in fact a major open end (under-determined). The restructuring of capital is a chief disciplining factor.

The result of the restructuring of capital (B-1 to B-4) is that the rate of internal profit for the remaining enterprises increases. By itself this is no sufficient impetus for extra investment, as long as there is no extra effective demand forthcoming, or at least an expectation of it.

\section{B-5 Cyclical 'hoarding' and implementation of techniques}

Because, through the restructuring of capital, the least efficient plants are scrapped, we have a reduction in the range of the stratification. ${ }^{22}$ With it, we saw, the structural overcapacity that was built up during the expansion is cut away.

Generally any successful new plant investment requires either extra demand (which is not the case in the recession) or a degree of productivity difference between the top and the bottom of the stratification. This difference should be such that the general overcapacity that emerges through that investment enforces the scrapping of plants down the stratification - so relieving the general overcapacity. Conversely the general range reduction through the restructuring has reduced this opportunity of productivity difference.

However, along the recession, when new plant investment does not come forth, research and development goes on but new technology is not implemented in new techniques. ${ }^{23}$ We so have a 'hoarding' of new techniques. When such a hoarding has been built up it pays at some point to invest in new techniques, with the intention that bottom plants are scrapped (this is the intention; however, in case a generalised renewed investment generates sufficient macroeconomic growth, this scrapping might not be forthcoming - see phase 1 , and its fragility alluded to in $5 \S 9-b)$. Hence, overall, we have a cyclical (de)concentration in the implementation of new technology.

22 See Figure 4.9 on the range of the stratification.

23 Even in severe recessions, enterprises tend to keep at least the core of their R\&D workers because the rebuilding of a $R \& D$ department takes enormous effort and time. (The main text puts primary emphasis on process innovation; however, the same applies for product innovation.) 
Note that, as for all of the above, this is a macroeconomic account. In a recession, some sectors may keep on investing even if at a lower scale, whence for these the hoarding also is a mitigated one.

B-6 Renewed bank credit

Because of the factors B-1 to B-4, banks are inclined to accommodate the investment projects B-5.

C

Early expansion (phase 1)

To the extent that the 'dishoarding' of techniques macroeconomically synchronises (and along with the factors B-1 to B-4) there arises a moderate though general boost of investment (without, initially at least, required scrapping). This provides the take-off to a new expansion (the early upturn phase, as presented in the previous section). ${ }^{24}$

5§9-a Addendum. Marx and Schumpeter on cyclical movement and 'neue Kombinationen'

Marx presents his exposition of the cyclical movement of capital in Capital I, Part Seven, and in Capital III, Part Three (Marx 1976 [1867], and 1981 [1894]). Schumpeter credits him not only for being the first business cycle theoretician, but also for detecting the phenomenon: 'We find practically all the elements that ever entered into any serious analysis of business cycles, and on the whole very little error. Moreover, it must not be forgotten that the mere perception of the existence of cyclical movements was a great achievement at the time' (2003 [1943], pp. 40-1).

The exposition of $5 \$ 9$ builds on Marx's major insight that in the recession the rate of profit is restored via destruction and devaluation of capital. However, Marx also posits that the competitive struggle in the recession impels the introduction of new methods of production. He cast this in terms of his famous phrase of 'neue Kombinationen' (new combinations) that inspired Schumpeter $(1934[1911]) .{ }^{25}$ In Marx's text it is not very clear as to whether these 'neue Kombinationen' start being applied in the recession or (mainly) in the upturn. Anyway, for Schumpeter this happens in the early upturn - to which I agree.

24 Compare Schumpeter who, in contradistinction to the current theory, provides no mechanism for the impetus to the upswing (see $5 \$ 9-a)$.

25 Marx 1972 [1894], p. 265: '... Anwendung neuer Maschinen, neuer verbesserter Arbeitsmethoden, neuer Kombinationen'. The English edition (Fernbach translation) uses the phrase 'new forms of combination' (1981 [1894], p. 363). 
However, neither Marx nor Schumpeter offer any account of why inventions are produced during the slump and implemented in the upturn. The argument above about 'hoarding' and 'dishoarding' of techniques is that innovations are produced all along, but that - on average - their implementation in the slump would not pay because the restructuring and centralisation of capital produces a decrease in the range of stratification, whence the dynamic competition between enterprises remains only latent (hoarding of innovations) until sufficient productivity difference between the (potential) top and the bottom of the stratification has been built up.

5§9-b Explication: Phases of the business cycle - a macroeconomic account

This explanation sets out the course of the business cycle in mainly macroeconomic terms. Figure 5.7 serves as a synopsis for it. Although this explication adds details to the outline of the main sections $5 \S 8$ and $5 \S 9$, the purpose is far from being exhaustive. It is meant to be in line with all of this book's purpose of setting out the main interconnections of the capitalist system. Now, however (as was already the case in Chapter 4), contingency creeps in increasingly.

I classified the cycle into six phases. This number is somewhat arbitrary (other accounts may adopt more or fewer phases).

Below I adopt the term CG sector (the sum of the consumer goods producing industries) and MP sector (the sum of the means of production producing industries, including the intermediate production), first introduced in $3 \S 2-\mathrm{a}^{26}$ Unless otherwise indicated the terms change/increase/decrease refer to comparison with the previous phase.

For all of the phases described below, it may be useful, as before, to keep in mind the equations for internal profit and the rate of internal profit.

$$
\rho=\frac{\mathrm{R}}{\mathrm{K}-\varepsilon \mathrm{K}}=\frac{\mathrm{I}+\mathrm{Ck}-\mathrm{Sw}-i \varepsilon \mathrm{K}}{\mathrm{K}-\varepsilon \mathrm{K}}
$$

26 The MP producing industries encompass far more than is measured by 'investment', as these include all of the 'intermediate' production. Very roughly today the intermediate production (of MP) is equivalent to the total of GDP, thus total gross production being twice GDP. (This varies depending on the structure of an economy; the number can be read off from the statistical input-output tables of a particular economy.) 

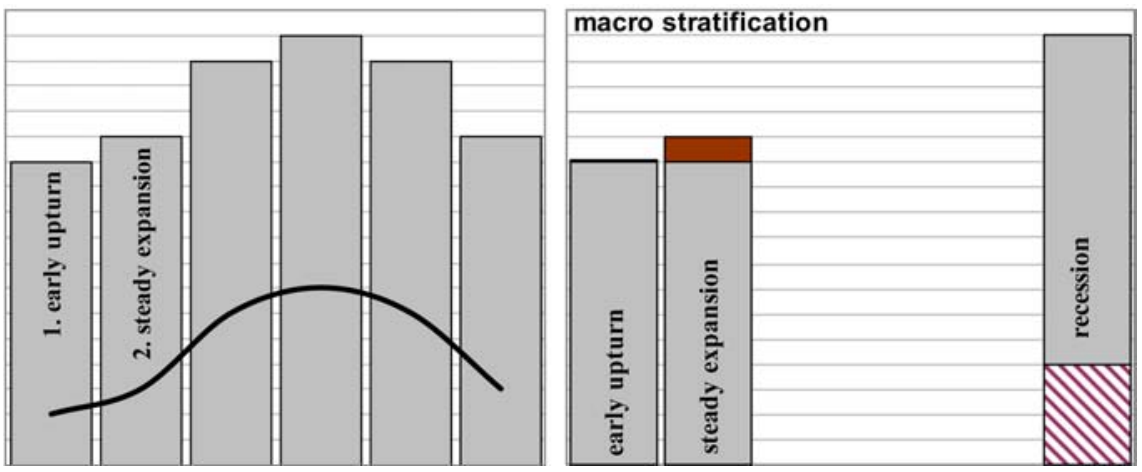

This first phase is inherently the most fragile one. (In so-called 'double dips', the fragility of the early upturn is such that we have a fall back into recession.)

- In the early upturn we have a moderate: $\mathrm{I} \uparrow$ and $\mathrm{L} \uparrow$, and hence $\mathrm{Y} \uparrow$. The lead for the increase in production is taken by the MP sector that initially increases the production of replacement investment, which next has a multiplier effect in net investment. The investment, as well as the production for it, embodies new techniques.

- The demand for additional replacement investment, and next the I, L and Y increasing production of it, is triggered by a combination of three factors, which is the result of the recession, whence their explanation must be postponed (see phase 6 and $5 \S 9$ ). Here I just mention these: (a) a restoration of the rate of profit due to a devaluating 'restructuring' of capital (through which inefficient plants/enterprises have been scrapped or eliminated) and through which the remaining plants can produce at near to full capacity; (b) for survived enterprises a further restoration of the rate of profit due to declined wages together with increased compliance; (c) 'hoarding' of techniques (dishoarded in the current early upturn). All these factors result in a rise in labour productivity.

- The restoration of the rate of profit provides confidence for banks to accommodate investment via additional PVF. The recession factors just mentioned are (further) effectuated in the early upturn. We also have a rise in productivity for plants that 'hoarded' labour-capacity. ${ }^{27}$

27 'Labour hoarding' (in fact labour-capacity hoarding) refers to the reluctance of enterprises to lay off in the recession the specialist echelon of their workers that may be difficult to replace by other workers in an expected upturn. Thus during the recession these are in part idle at a perhaps full wage. 
- Although the PVF rises, the RPFV tends to be constant in comparison with its strong decline in the previous phase: the slim savings by capital owners (due to thin distribution of profits) and by the employed (due to decreased wages) more or less outweigh the dissaving by, or for, the unemployed.

- The previous strong decline in R PVF, together with the decreased risk in face of the previous restructuring of capital, mean that the rate of interest is at a low ebb, whence the RPVF leverage effect (for the existing $i \varepsilon \mathrm{K}$ ) is positive.

- The merely moderate increase in investment means that there is hardly any overcapacity.

- In sum, profit $(\mathrm{R})$ rises - mainly due to the investment effect - and its rate of increase is larger than the rate of increase of capital accumulated $\left(\mathrm{R}^{\prime}>\mathrm{K}^{\prime}\right)$ whence the rate of internal profit $(\rho)$ rises.

\begin{tabular}{c|c|c|c|c|c}
\hline \multicolumn{3}{c}{ Early upturn } \\
\hline finance & general & $\begin{array}{c}\text { determinants } R P V F \\
\text { and expenditure }\end{array}$ & \multicolumn{3}{|c}{ results } \\
\hline $\begin{array}{c}\text { PVF } \uparrow ; \\
\text { RPVF } \approx \text { const. } \\
\text { RPVF lever: pos. }\end{array}$ & $\begin{array}{c}\mathrm{I} \uparrow, \mathrm{K} \uparrow ; \mathrm{L} \uparrow ; \mathrm{Y} \uparrow \\
\text { hesitating growth } \\
\mathrm{I}^{\prime}>\mathrm{K}^{\prime}\end{array}$ & Sk and Sw $\approx$ const. & $\emptyset \approx$ const. & $\mathrm{R}^{\prime}>\mathrm{K}^{\prime}$ & $\begin{array}{c}\mathrm{R} \uparrow ; \rho \uparrow \\
\text { hesitating }\end{array}$ \\
\hline
\end{tabular}

$\mathrm{x}^{\prime}=$ rate of growth of $\mathrm{x}$

\section{$2 \quad$ Steady expansion}

Based on the increased rate of profit and the cuts of overcapacity we have in this phase a steady growth of macroeconomic investment, employment and income. Generally there is a restored confidence and optimism about the future. For the management of enterprises, the previous crisis and recession gradually moves to the back of their minds. On the other hand, much of labour is still distressed with unemployment even if its rate decreases.

Through investment there is a net addition of plants along with a moderate increase in capacity, which takes it near to the desired capacity. Whereas the PVF increases along with the employment and investment, there is also a modest increase in the RPVF because of a gradual modest increase in savings on the part of capital owners. The interest rate is still near to its low ebb, whence the RPVF leverage effect is positive. The sum of profits $(\mathrm{R})$ rises steadily due to the investment effect. Its rate of increase is larger than the rate of increase of capital accumulated $\left(R^{\prime}>K^{\prime}\right)$ whence the rate of internal profit $(\rho)$ rises. 


\begin{tabular}{c|c|c|c|c|c}
\hline \multicolumn{5}{c}{ Steady expansion } \\
\hline finance & general & $\begin{array}{c}\text { determinants } R P V F \\
\text { and expenditure }\end{array}$ & \multicolumn{3}{|c}{ results } \\
\hline $\begin{array}{c}\text { PVF } \uparrow \\
\text { RPVF } \uparrow: \text { modest } \\
\text { RPVF lever: pos. }\end{array}$ & $\begin{array}{c}\mathrm{I} \uparrow, \mathrm{K} \uparrow ; \mathrm{L} \uparrow ; \mathrm{Y} \uparrow \\
\text { steady growth } \\
\mathrm{I}^{\prime}>\mathrm{K}^{\prime}\end{array}$ & $\begin{array}{c}\mathrm{Sk} \uparrow \\
\mathrm{Sw} \approx \text { const. }\end{array}$ & $\begin{array}{c}\text { ø approaching } \\
\text { desired rate }\end{array}$ & $\mathrm{R}^{\prime}>\mathrm{K}^{\prime}$ & $\begin{array}{c}\mathrm{R} \uparrow ; \rho \uparrow \\
\text { hesitating }\end{array}$ \\
\hline
\end{tabular}

This is the phase of a generally violently increasing accumulation and growth. Investment fiercely accelerates based on the previous phase's increased rate of profit and the narrow overcapacity. Enterprises hate to miss the opportunities. The CG sector (consumer goods) swings and reinforces the MP sector's growth. Considering the investment effect on profits taken in isolation, the growth in profits accelerates $(\mathrm{R}=\mathrm{I}+\mathrm{Ck}-\mathrm{Sw}-i \varepsilon \mathrm{K})$. Investment considered in isolation would also positively affect the rate of internal profit ( $\rho)$, because the rate of growth of investment (and hence profits) is larger than the rate of growth of accumulation $\left(I^{\prime}>K^{\prime}\right)$. However, each of these effects is mitigated by the savings effect by itself $(\mathrm{Sw})$ via expenditure, and by saving effects (Sk and $\mathrm{Sw}$ ) on the RPVF and hence on $i \varepsilon \mathrm{K}$.
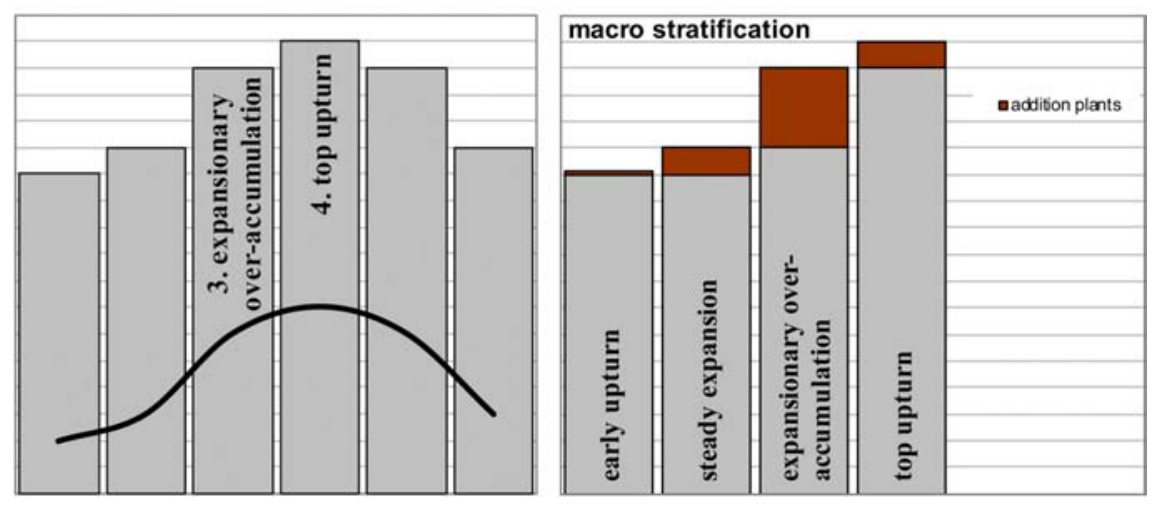

First, the acceleration in investment goes along with both an increase in employment and an increase in the wage rate (together $\mathrm{wL}$ ). The extra saving from it $(\mathrm{Sw})$ directly mitigates the profits $(\mathrm{R})$. Second, the growth in both investment and wages is conditioned on an increasing PVF from banks. This will go 
along with a disproportionate rise in the RPVF because of extra saving by capital owners (Sk) from increased distributed profits, and because the extra savings out of wages, as mentioned (Sw). This rise in RPVF affects the external finance $(i \varepsilon \mathrm{K})$ in volume $(\varepsilon \mathrm{K})$ as well as in price $(i)$ because of the extra risk premiums required by banks and other financiers. The RPVF lever on the rate of profit moves down, or is perhaps becoming negative (this depends on the concrete situation and may be different for specific cycles).

As indicated in the main text, the net effect of these factors on the rate of internal profit is an empirical matter. Decisive for the next phase is that the (inherently uncoordinated) broad increase in investment also generates vast overcapacity.

\begin{tabular}{|c|c|c|c|c|c|}
\hline \multicolumn{6}{|c|}{ Expansionary over-accumulation } \\
\hline finance & general & determinants $R P V F$ & \multicolumn{3}{|c|}{ results } \\
\hline $\mathrm{PVF} \uparrow$ & $\mathrm{I} \uparrow$ violent; $\mathrm{K} \uparrow ; \mathrm{L} \uparrow ; \mathrm{Y} \uparrow$ & $\mathrm{Sk} \uparrow ; \mathrm{Sw} \uparrow$ & \multirow{3}{*}{$\begin{array}{c}ø \uparrow \\
\text { steep }\end{array}$} & \multirow[t]{3}{*}{$\mathrm{R}^{\prime} \approx \mathrm{K}^{\prime} ?$} & \multirow{3}{*}{$\begin{array}{c}\mathrm{R} \uparrow \\
\rho \approx \text { constant? }\end{array}$} \\
\hline $\mathrm{RPVF} \uparrow$ : heavy & increasing growth & & & & \\
\hline RPVF lever: $\downarrow$ & $\mathrm{I}^{\prime}>\mathrm{K}^{\prime}$ & & & & \\
\hline
\end{tabular}

The macroeconomic rate of overcapacity $(\varnothing)$ is a measure for the macroeconomic over-accumulation. The current phase was characterised as 'expansionary over-accumulation'. In fact, actors (as well as the economist-spectator) usually perceive the over-accumulation only towards the end of this phase or perhaps halfway. However, even if enterprises might perhaps have some earlier inkling that their investment could be excessive, they will most often be reluctant to leave the floor to competitors. All the enterprises that withdraw miss out against those that do not, especially if the latter are few. Cyclical overaccumulation of capital is at the edge of being the necessary form of accumulation. Grand cartels, sector monopolies forming inter-sector cartels or in the end one grand monopoly might perhaps prevent it.

The top of expansion and turning point

Even if at the end of the previous phase the rate of internal profit would have been increasing instead of damping or stagnant, investment falls back because of overcapacity. Even at a comparatively high rate of profit, it makes no sense to invest when this increases the overcapacity still further $(5 \S 5$, heading 2$)$. 
Macroeconomically there may still be a moderate investment because of running investment plans and investment orders, and also because some enterprises remain optimistic about sales and the rate of profit. Given that individual investments are most often complementary to others, once the plans are definite and investment purchase orders have been placed, investments are rather fixed for $(t)$ and $(t+1)$ or even longer. ${ }^{28}$

The fall back in investment is the decisive characteristic of this phase, and the one that makes the business cycle turn downward. Because investment expenditure decreases sharply, profits (R) go down sharply in comparison with the previous phase. At the same time, because L keeps increasing (though mitigated), wages keep increasing (non-mitigated). Hence saving out of wages $(\mathrm{Sw})$ increases, which also negatively affects the validation of surplus-value and hence profit.

Whereas the PVF decreases in comparison with the previous phase (it increases due to the increased wage sum, but decreases more due to the decreased investment), the RPVF nevertheless increases modestly due to the Sw increase, which is counteracted by a decrease of Sk because of a decrease in profits distributed. This volume effect of external finance, along with the increased risk of it, makes the interest rate rise so that the leverage effect of external finance goes further down.

As a result, profits and the rate of internal profit decline sharply (cf. equation 5.5). Once the seriousness of the constellation is apprehended (perhaps in the second half of this phase), it is not evident what actions the smaller echelons of enterprises should take in reaction to this. Large to very large enterprises, by contrast, are in a position to start undertaking cost-cutting reorganisations. As indicated in $5 \S 8$ they will tend to, selectively, slow-down their replacement investment as well as their hiring of labour-capacity (hence we have for those enterprises/plants a slow to negative rate of growth for each). The macroeconomic multiplier effect of these actions takes off the remaining growth and puts an end to the general expansion.

28 In this context Kalecki (1971 [1933], pp. 2-4) distinguishes between 'investment orders', 'production of investment goods' and 'deliveries of finished equipment' (see also the discussion by López and Assous 2010, pp. 29-30). 
Top of expansion and turning point

\begin{tabular}{c|c|c|c|c|c}
\hline finance & general & $\begin{array}{c}\text { determinants RPVF } \\
\text { and expenditure }\end{array}$ & \multicolumn{3}{|c}{ results } \\
\hline $\begin{array}{c}\mathrm{PVF} \downarrow \\
\mathrm{RPVF} \uparrow \text { (modest) } \\
\mathrm{RPVF} \text { lever } \downarrow\end{array}$ & $\begin{array}{c}\mathrm{I} \downarrow ; \mathrm{K} \uparrow ; \mathrm{L} \uparrow ; \mathrm{Y} \uparrow \\
\text { slow-down of growth) } \\
\mathrm{I}^{\prime}<\mathrm{K}^{\prime}\end{array}$ & $\mathrm{Sk} \downarrow ; \mathrm{Sw} \uparrow$ & $\varnothing \uparrow$ & $\mathrm{R}^{\prime}<\mathrm{K}^{\prime}$ & $\mathrm{R} \downarrow ; \rho \downarrow$ \\
\hline
\end{tabular}
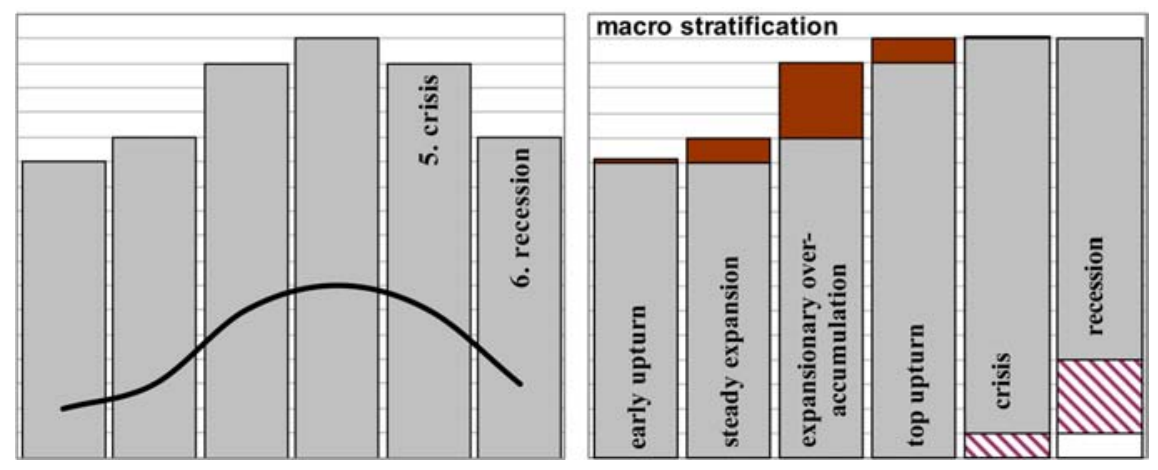

5

Crisis (early recession)

I will not repeat here the main outline of this phase, which was, for the current purposes, sufficiently described in the main text of $5 \$ 9$ (introduction and under subsection A). Here I briefly expand on the spiralling down process of this and the next phase, as well as on some details for the current phase regarding the macroeconomic profit $(R)$ and profit rate $(\rho)$.

The downfall in investment of the previous phase first hits the sales of the MP producing sector, and so the rise in unemployment starts here. The effect is a decline in consumption, which affects the sales of the CG producing sector whence it cuts back production, and lays off labour. This re-affects its own sales. In response this sector will cut back on replacement investment, so re-affecting the means of production producing sector. And so forth. This is the spiral down process that was alluded to in the introduction of $5 \S 8$, and the reason for the statement that the capitalist system is not suited to cope with declining and shrinking economic activity. (As indicated this applies for the crisis phase and especially also for the recession discussed in the next subsection under phase 6.) 
In the current early recession we have the first bankruptcies of small enterprises. Next to it the reorganisations started by the middle and large enterprises in the previous phase now mature into the scrapping of plants down the stratification. This implies that we have a decrease in the capital accumulated $(\mathrm{K})$ and hence also a decrease in overcapacity. Because $\mathrm{K}$ declines, and although the macroeconomic profit $(\mathrm{R})$ decreases, the rate of internal profit tends to be roughly constant - that is, in comparison with the sharp decline in the previous phase 4. The net decline in profit stems from, first, the investment expenditure effect (negative), second, a modest positive effect from decreased saving out of wages, and third, an increase in the interest on the RPVF. Although the RPVF volume modestly decreases, the sharp decline in $\rho$ from the previous phase, which now endures at that low ebb, means that debt extensions require a riskmotivated higher interest rate.

\begin{tabular}{c|c|c|c|c|c}
\hline \multicolumn{5}{c}{ Crisis (early recession) } \\
\hline finance & general & $\begin{array}{c}\text { determinants } R P V F \\
\text { and expenditure }\end{array}$ & \multicolumn{3}{|c}{ results } \\
\hline $\begin{array}{c}\mathrm{PVF} \downarrow \\
\mathrm{RPVF} \downarrow \text { : modest } \\
\mathrm{RPVF} \text { lever: negative }\end{array}$ & $\begin{array}{c}\mathrm{I} \downarrow ; \mathrm{K} \downarrow ; \mathrm{L} \downarrow ; \mathrm{Y} \downarrow \\
\text { fast decreases } \\
\mathrm{I}^{\prime}=0 ; \mathrm{K}^{\prime}<\mathrm{O}\end{array}$ & $\begin{array}{c}\mathrm{Sk} \approx \text { const.; } \\
\mathrm{Sw} \downarrow\end{array}$ & $\emptyset \downarrow$ & $\mathrm{R}^{\prime} \approx \mathrm{K}^{\prime}<0$ & $\begin{array}{c}\mathrm{R} \downarrow ; \\
\rho\end{array}$ \\
\hline
\end{tabular}

In effect, as we will see below, the recession prepares the conditions for a renewed accumulation of capital (in the early upturn of phase 1). In the recession phase we have a continuation of the restructuring of capital (ROC), initiated by large enterprises at the end of the upturn. Now we have a generalised and enforced ROC as well as centralisation of capital. The enforcement is due to a growing number of enterprises being at the edge of bankruptcy and that for others the rate of internal profit is at a low ebb or negative (phases 4-5).

ROC: intra-enterprise reorganisation and inter-enterprise centralisation of capital. Generally the duration and the intensity of the ROC (and hence the duration and intensity of this phase) depend on the intensity of the overaccumulation of phase 3 . There are many possible forms of Roc. These include the reshuffling of the departments of an enterprise but also the closing down of plants or perhaps particular departments of plants. However, this Roc may also be combined with inter-enterprise reorganisations. In that case it is combined 
with the selling and buying of plants between enterprises or with take-overs or with mergers (followed each time by, then, intra-enterprise reorganisation). This inter-enterprise reorganisation is called 'centralisation of capital'. This term (stemming from Marx) is appropriate as the governance of enterprises moves from local in degree to central in degree. ${ }^{29}$

Actual bankruptcies, as well as the closing down of plants, means that we have in part a destruction of what was built up in the previous upturn of the cycle. Much of the previous labour employment growth is extinguished into unemployment. From the point of view of enterprises we have, along with the physical counterpart, a destruction of capital, an annihilation of previous accumulation (hence $\mathrm{K} \downarrow$ ). ${ }^{30} \mathrm{In}$ terms of the stratification of capital we have an enforced shortening of the range of stratification as the least efficient plants get scrapped (cf. Figure 4.9 on the range of the stratification).

Further effects of ROC. Along with these pure capital effects, the concomitantly increasing unemployment gives rise to wage rate decreases. This implies not only a vast decline in saving from the employed, but also dissaving from the part of those unemployed who had built up savings previously (or, in case these are lacking, from relatives, for example). Along with it the RPVF declines, which pushes the profits for the remaining enterprises. This profit push somewhat compensates for the primary negative effect on profit, which stems from investment approaching nil (a continuation from the previous phase).

At the same time unemployment, or the threat of it, also enforces a 'disciplining' and compliance of labour during production $(2 \S 5$, Figure 2.4$)$, which in effect increases the productivity of labour.

These effects on capital and labour together constitute the 'curing' effect of the recession. In sum, so far, the vast destruction/devaluation of capital from the Rос means that even if profits are at a very low level, the rate of internal profit increases for the remaining enterprises.

This increase is reinforced by the following finance factors. First, because of the decreased saving (from the part of labour, and from the part of capital owners as a continuation from phase 4 onwards), the running PVF - for wages - is near to fully redeemed by enterprises. Second, the restructuring bankruptcies imply that banks, and other external financiers, have to write off their loans, whence the RPVF decreases. Third, the balance sheets of the production enter-

29 In mainstream economics this is called 'concentration'. (Marx also uses the term concentration, but rather for the growth of enterprises - big enterprise, i.e. local growth. See Marx, Capital I, Ch. 25; German edition Ch. 23).

3o Regarding Roc, and up to this point of the text, I take inspiration from the work of Fine and Harris (esp. 1979, pp. 83-7) and Weeks (1981, pp. 208-13). 
prises have been cleaned up, whence for the existing RPVF the risk of banks is moderated. These factors, together with their favourable effect on the rate of profit, mean that banks are increasingly prepared to charge a lower rate of interest on debt extensions (just the opposite of the previous two phases). This means that the leverage effect now starts becoming positive.

\begin{tabular}{|c|c|c|c|c|c|}
\hline \multicolumn{6}{|c|}{ Recession } \\
\hline finance & general & determinants $R P V F$ & \multicolumn{3}{|c|}{ results } \\
\hline $\begin{array}{c}\text { PVF } \downarrow \\
\text { RPVF } \downarrow \text { : strongly } \\
\text { RPVF lever: towards } \\
\text { positive }\end{array}$ & $\begin{array}{l}\text { I const. (o); } \\
\mathrm{K} \downarrow ; \mathrm{L} \downarrow ; \mathrm{Y} \downarrow \\
\text { all rickety } \\
\mathrm{I}^{\prime}=\mathrm{O} ; \mathrm{K}^{\prime}<\mathrm{O}\end{array}$ & $\begin{array}{c}\text { Sk } \approx \text { const.; } \\
\text { Sw } \downarrow\end{array}$ & $\varnothing \downarrow$ & $\mathrm{R}^{\prime}>\mathrm{K}^{\prime}<\mathrm{O}$ & $\begin{array}{c}\mathrm{R} \approx \text { const.; } \\
\rho \uparrow\end{array}$ \\
\hline
\end{tabular}

The curing in the recession provides a precondition for recovery and renewed accumulation of capital. However, it is not evident at all what might take off

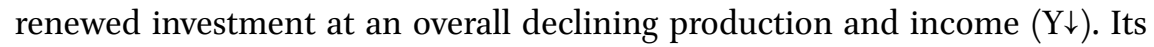
key lies in range of the stratification of capital and the (dis)hoarding of new techniques as explained in $5 \S 9$, heading D.

5§9-a Addendum. An immanent appreciation

Generally this book presents an immanent critique of the capitalist system, that is, from its own norms. It so leaves any further appreciation to the reader. From its own norms (in brief, the monetary-value dimension and the rate of profit as criterion for economic activity, which engenders the motive for accumulation of capital for the sake of accumulation of capital), the cyclical movement of the accumulation of capital is at least paradoxical. The accumulation of capital recurrently results in a great deal of annihilation of that accumulation. This is so continuously (the continuous scrapping as presented in Chapter 4) but especially cyclically. Individual enterprises and capital owners always hope to escape the dance. However, only few corporations survive a long series of cycles. In jointly over-accumulating capital (phase 3 ), enterprises do no more than applying the 'logic' of the system that they so reinforce.

On an individual level, capital owners take a risk of their own free will (the big ones can spread that risk) and may win or lose. Workers, however, do not take a risk of their own free will: lacking command over means of production 
and access to sufficient bank loans, they are forced to sell their labour-capacity and get 'employed' (used) under penalty of starvation. That is immanent to the system. Being used along with wage increases and again wage decreases is one thing. However, it is also immanent to the system that the uppermost dark side of its cyclical movement gets concentrated within one particular echelon: those that are laid off to be unemployed.

Further, it is questionable - to say the least - as to how long the cyclical overaccumulation and destruction of capital is physically sustainable in terms of the climate and natural resources. The monetary-value dimension and the rate of profit merely measure what they do measure and thus what is subsumed under these measures.

\section{Summary and conclusions}

This chapter has set out the concrete manifestation of the earlier exposition in the cyclical movement of capital. We have seen how the production and accumulation of capital concretely takes the form of this cyclical movement. Its exposition synthesised many of the treads of the earlier exposition (Chapters 1-4) at this concrete level. However, as economic reality is inevitable always actual in some phase of this movement (one phase of the business cycle), its exposition is also a concrete synthesis of the earlier exposition.

Division ${ }_{5}$ Di presented concretising connections from the earlier chapters to the current one, especially that of the macroeconomic 'internal profit' of enterprises and the 'rate of internal profit', each of which accounts for the external finance of enterprises and its (de)leverage effect. Investment being the main locomotive for the cyclical movement, the rate of internal profit as bounded by the rate of overcapacity were presented as the core macroeconomic determinants of investment decisions. The final section of this division presented a condensed macroeconomic sequence of production predicated on bank finance, of validation by expenditure, of distribution of surplus-value to external financiers and of the resulting rate of internal profit.

Division ${ }_{5} \mathrm{D} 2$ set out how phase-wise series of these sequences cyclically develop from phases of expansion $(5 \S 8)$ into phases of crisis and contraction $(5 \S 9)$. In this cyclical movement, the capitalist systems' immanent expansive forces generate over-accumulation of capital $(5 \S 8) \cdot{ }^{31}$ In the crisis and recession,

31 This is an almost necessary process. 'Almost': in $5 \S 9$-b, at the end of the account for phase 3 , it was indicated that grand cartels and monopolies (in fact a privately planned capitalist economy) might possibly outstrip this necessity. 
this is violently cured by destruction of capital that prepares the conditions for a renewed expansion and again contraction $(5 \S 9)$. That is, inwardly bifurcated productive activity is cyclically destroyed. With it the applied natural resources are destroyed - those that are accounted for in the monetary-value dimension (MVD) as well as those that are not. Along with the destruction of productive activity and productive capacity, employment of labour is destroyed. The misery is condensed in those who are expelled into unemployment. Predominantly these, and their children, are sacrificed for the process of 'creation and destruction'. Even if during this Sisyphean process the average real income per head may increase, the heads are not equal and the unemployed in particular are 'hors catégorie' in this respect.

\section{Chapter 5 in the perspective of Chapters 1-4}

The MVD determined bifurcated production (Chapter 1) enforces accumulation of capital (Chapter 2) as conditioned by bank finance and next the (in part) ex post substitution for it (Chapter 3). Because the competitive dynamic interaction between enterprises is ultimately battled out in production, and because enterprises are out to optimally preserve their capital accumulated, the structure of production tends to be stratified according to the value-productivity of labour and rates of profit $\left(4 \mathrm{D}_{1}\right)$. This structure, therefore, is a main focus for the exposition of the cyclical movement of capital. As indicated, the rate of internal profit is the core determinant of investment decisions and the cyclical movement (as bounded by the rate of overcapacity). Like its twin of the 'rate of integral profit' (with surplus-value at its base, first posited in $1 \S 13$, cf. $5 \S 1$ ) - it is the concentration of the determinants that were developed so far (Part One), as it is in the everyday practice of enterprises. It is the reflection of the concrete internally bifurcated process of production of capital; that is, labour's production of capital through the production of surplus-value $\left(\Pi=\mathrm{mL}^{\alpha}-\mathrm{wL}\right)$ for the owners of capital - the productive power of labour $(\alpha)$ being the prime mover $(1 \S 14)$. The point is indeed that practically abstract entities (i.e. abstractions in practice, $1 \S 4,1 \S 4-\mathrm{b}$ ) - that is, monetary value and the rate of profit - determine the capitalist world as it concretely appears in our experience as including the economic high and low tides.

Whereas labour is the prime mover of the production of value and capital, capital itself is the prime mover of its cyclical course of accumulation and again the partial annihilation of this accumulation - labour is passively confronted with the ups and downs of employment and unemployment.

Banks are a top-level institutional determinant of the capitalist system (money as presented in $1 \S 4$ was concretised as bank-issued money in $2 \mathrm{D}_{4}$ ). Banks are the only originator of the external finance of enterprises (as well as of 
their internal finance). The bank-provided PVF is a continuous capitalist necessity $\left(2 \mathrm{D}_{4}, 3 \mathrm{D} 2\right)$. To the extent that there are savings - the big financial nuisance for enterprises - there is a non-redeemed part of the PVF (the $\triangle \mathrm{RPVF}$ equal to the $\Delta \varepsilon \mathrm{K}$ ), which needs to be substituted for, in part, by other external financiers. The degree of saving so affects the required degree of external finance. This is reflected in the rate of interest. Its variation over the cycle determines whether external finance acts as a (de)leverage on the rate of internal profit.

On average, saving out of wages negatively affects the validation of surplusvalue $(3 \S 10)$, and so the resulting profit $(5 \S 1)$. Because the savings ratio out of wages varies over the phases of the cycle, this affects the resulting profit phase-wise (negatively in the second half of the expansion and positively in the recession). Savings out of wages are - directly or indirectly - a last resort for the unemployed. From the point of view of labour, the cyclical movement of capital develops behind their backs. Producing capital for the owners of capital is immanent to the capitalist economy $\left(\mathrm{ID}_{5}, 5 \S 8\right)$. We have now seen that along with the recessive annihilation of their product, labourers are hit by the scourge of unemployment - all potentially, many actually. This is equally immanent to the capitalist economy $(5 \S 9)$. From the sweat of one's brow to redundancy and pauperism.

\section{Appendix 5 A. On the particular structural background of the 2008 crisis $^{32}$}

\section{Introduction and synopsis}

No cycle, including its crisis, is identical to the previous one. Chapter 5 indicated their general pattern. However, the 2008 crisis and its aftermath is no cyclical phenomenon. The 2008 financial-economic crisis in especially the EU and the USA results from a structural change that developed from the early 1980s onwards (see below). The extended recession period following it combines, first, the aftermath of this structural change, and second, the restructuring of capital that is characteristic of a 'normal' recession.

This structural change combines two main issues. First, a considerable shift in the macroeconomic distribution of income between capital-labour in favour of capital income (which 'normally' would have a negative effect on consumption expenditure). Second, a shift in the structure as well as the size of bank

32 This appendix is based on an article that appeared in Science and Society (Reuten 2011). The current version is more refined and also corrects some mistakes (for which I apologise). 
credits, the latter involving vastly increased credits to consumers/wage earners. The latter so maintained or even increased their consumption (counteracting the wage effect).

Within this period of structural change (i.e. from the early 1980 os to 2008), we had the 'normal' cyclical alternation, though with modifications regarding the destination of the PVF, and of the sources of savings and the RPVF.

Below this structural change is phrased in terms of a 'postponement of stagnation'. While the policies of banks played the core role in postponing the stagnation, the roots of the crisis are located at a deeper level. The implication is that the economic problems are much more difficult to overcome than the usual analyses suggest.

I hesitated over whether I should include this Appendix at this point or rather at the end of Chapter 10. The point is that the empirical figures below are - evidently - predicated on the existence of the state (even if rather implicitly) as well as on policies concerning, for example, unemployment payments (presented in Part Two). I finally decided to include it here, first, because the subject intimately relates to the finance of capital (Chapter 3 ) and especially the course of the cyclical movement of capital (Chapter 5 ), and second, because the structural changes referred to mainly developed independently of state policy - or rather because the state (in fact many states) mainly refrained from legislation on this matter (i.e. the structural causes including the role of banks).

\section{$5^{\mathrm{A}-1} \quad$ The general constellation}

This appendix considers the era of so-called 'neoliberalism' (from about 1980) until the year 2010 and in comparison with the two decades prior to it (196080 ). Graph 5.8 shows graphs for various variables as a share in the GDP of the USA and the EU-15 countries. ${ }^{33}$

Investment. Of the variables shown, investment is the best measure for the cyclical movement. However, because the graphs show its share in GDP, the cyclical volatility of investment is flattened out (as for all these variables). ${ }^{34}$ From 1980 onwards the average investment share was roughly constant in the $\mid \mathrm{EU}-15$ and declined in the USA.

33 The EU-15 are the 15 countries that made up the European Union until 2004 (statistically this is a useful group because much of the relevant data for these countries often go back to 1960$)$.

34 GDP shares show changes of one variable relative to the change of another. One advantage of measurement in GDP-shares is that we need not correct for price inflation. 


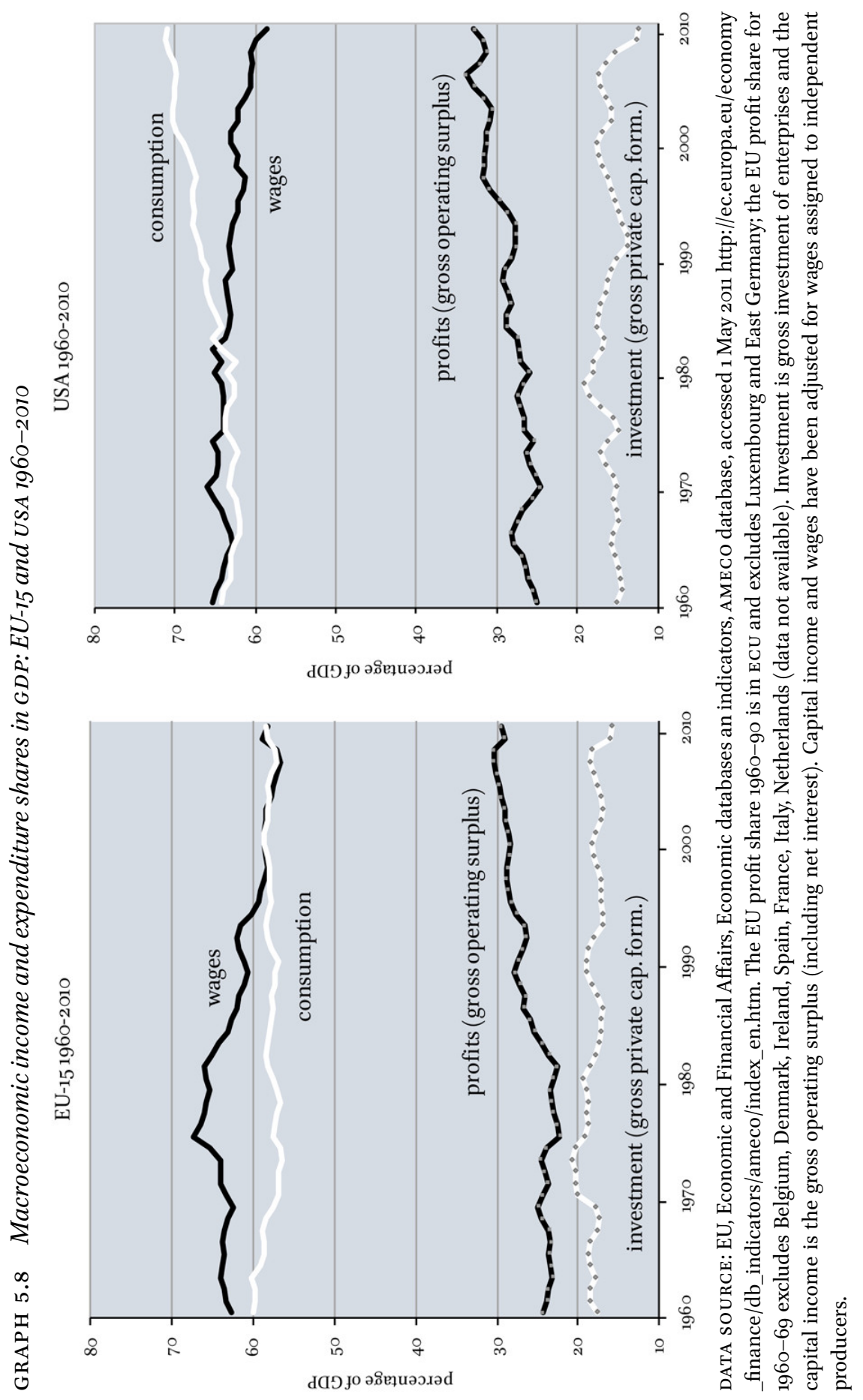


Wages. From about 198 o the wages share decreases considerably in the USA and vastly in the EU-15 countries. This structural change relates to developments in the labour market and the production aspects of income determination. ${ }^{35}$ In brief, the enduring vast unemployment following on from the severe 1981-82 recession shifted the balance of power between enterprises and labour, such that wage increases could continuously be held below labour productivity increases.

Consumption. Remarkably the wages share decrease is not reflected in a consumption share decrease. The latter slightly increased in the EU-15, and vastly in the USA. For the reasons set out in $5 \S 2$ I take it that the $\mathrm{Ck}$-share (from capital income) is roughly constant. The next section expands on the consumption by wage earners $(\mathrm{Cw})$.

Surplus-value. The share of the operating surplus shown in the graphs is merely a very rough indicator for the share of surplus-value in GDP (this is due to the way in which the National Accounts are constructed - see $3 \S 10-b$; Chapter 3 , App. $3 \mathrm{C}$, $\S 3 \mathrm{C}-1$ under point 6 , and in $8 \S 6-\mathrm{e})$.

Recall (from $3 \S 10$ or $5 \S 2$ ) the following equations for the realisation of surplus-value.

$\Pi \triangleleft=\mathrm{I}+\mathrm{Ck}+(\mathrm{Cw}-\mathrm{W})$

$\Pi \triangleleft=\mathrm{I}+\mathrm{Ck}-\mathrm{Sw}$

- For the EU-15 we had a vast decrease in the W-share (from 1980 in total about 1o percent), with the $\mathrm{Cw}$-share roughly constant, which accounts for a great deal of the rise in the П-share.

- For the USA we had a more moderated W-share decrease together with a vastly increasing $\mathrm{Cw}$-share (a gap moving to $10 \%$ in 2008). Together these equally account for a great deal of the rise in the П-share.

- This is the broad picture - I abstract from the effects of changes in state expenditure and from those of the foreign sector.

\section{$5^{\mathrm{A}-2} \quad$ From declining savings out of wages to 'colonisation of the future'}

Refer to Chapter 3 for Circuits 3.9 and 3.18 that are here reproduced, with in the last circuit an extra column added at its outer right ('or colonising postponement'). Regarding Circuit 3.9 recall that saving out of wages (as well as those out of capital income distributed) account for an increase in the debt of enterprises (the $\triangle \mathrm{RPVF}$ ). ${ }^{36}$ To the extent that saving out of wages decreases (spending

35 There are four determinants for the distribution of income: (1) the labour market; (2) production; (3) price setting; (4) expenditure. (This fourfold determination has been forcefully stressed by Bellofiore - e.g. 1999, pp. 64-5.)

36 Recall also that ex post the initial finance by banks (the PVF), capital owners or wage 
CIRCUIT 3.9 (reduced). Prevalidating finance $(P V F)$ by banks for wages: case of savings out of wages

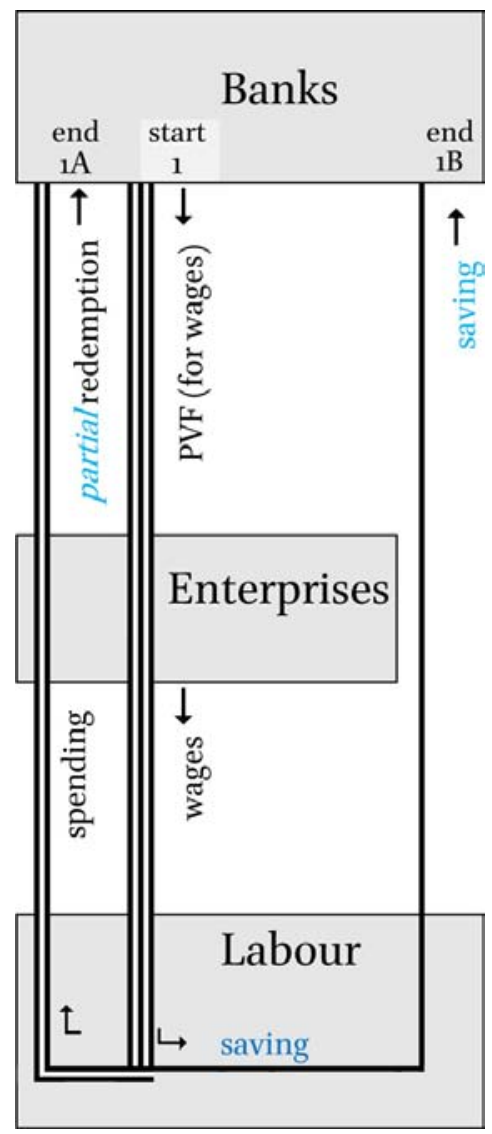

CIRCUIT 3.18 Enterprises'saving on PVF for wages due to consumer credit: case of zero saving out of wages (outer right column added)

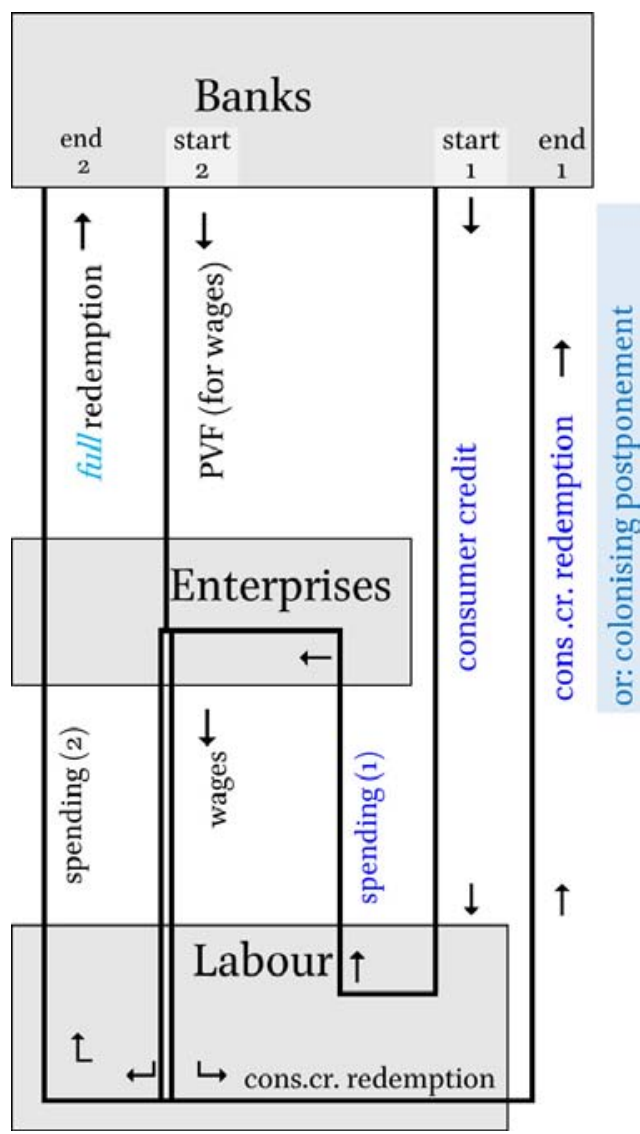

consequently increases), this source of the debt of enterprises decreases. Declining saving out of wages therefore affects the distribution of surplus-value

earners might substitute for the enterprises' stock of debt with banks, for example, by buying bonds from enterprises (either directly or indirectly, for instance, via pension funds). Pending such a substitution, the triadic credit-debt relationship between banks, enterprises and labour is normally favourable for banks in terms of interest margins. 
between banks and production enterprises, in favour of the latter. ${ }^{37}$ This is a partial effect (see the end of this section).

The further step is the movement of consumption beyond wages (see Circuit 3.18). This divergence was financed by direct consumption credit and by indirect consumption credit via mortgages - the latter in face of (expected) increasing collateral value. For the first time in history we saw consumption being financed on a massive scale by banks and next, in securitised form, substituted for by wealthy financiers, mostly via hedge funds. In this way, workers 'compensated' what they had lost on the wage front. All along, this prevented aggregate demand stagnation, even if this was not the motive.

However, loans require interest and must, at some point, be redeemed. Hence the banks - as well as other financiers via the banks - made claims on future wages of labourers. Lysandrou (2009) aptly called this the 'colonisation of the future'. Because this implies less future spending, the effect was a postponement of stagnation.

Note that Circuit 3.18 shows the simple case of an immediate redemption of consumer credit out of wages. This is the case of the pure substitution of consumer credit for PVF. In actual fact this redemption was - and remains postponed, resulting in a stock of debt owed to banks by workers: the colonisation of the future.

I indicated that declining saving out of wages affects the distribution of surplus-value between banks and production enterprises, in favour of the latter. This is a partial effect because the surplus-value distributed to capital owners vastly increased (compare the shares in GDP of investment and the operating surplus). Given the capital owners' stable consumption, this accounts for a structural savings increase, and hence an increased RPVF from their part (compare $3 \S 6$ and Circuit 3.13). The effect on the RPFV of the two saving categories might well balance out.

\section{$5^{\mathrm{A}-3}$ Conjunction of interests}

Due to a conjunction of interests, all the elements for this postponement of stagnation seemed to fit, that is, until about $2007 .^{38}$

37 Where other financiers partially substituted for the stock of debt (i.e. an ex post substitution for the non-redeemed part of the PVF), it is of course these financiers that receive a smaller share of surplus-value.

38 I am not arguing that the grand process of financing the divergence between wages and consumption was a concerted action. I merely indicate that there was a temporary, contingent fit so that no interest group had a motive for behaving differently. 
First, the direct beneficiaries were enterprises. After the initial and continuing wages moderation - that of wages growth lagging behind labour productivity increases - enterprises saw a decrease in the proportion of saving out of wages and hence, through higher spending, a decrease in the stock of debt owed to banks (Circuit 3.9). Presumably, though, this was roughly balanced out by increased saving from the part of capital owners. On top of this, once banks provided workers-consumers with consumer credit that was spent with enterprises, there was - for an amount equal to the amount of consumer credit an $e x$ ante substitution for PVF. Thus consumers took on a part of the credit that banks 'normally' would have provided to enterprises (Circuit 3.18). ${ }^{39}$ On the other hand, due to the increased distribution of surplus-value to non-bank financiers, the PVF for those must increase. In sum, enterprises pay lower wages, without being punished in terms of lower consumption expenditures.

Second, supposing that the PVF effect as well as RPVF effects cancel out (first, above) banks won in interest from labour (their share in wages). Further, for those mortgages that banks resold via securitisation, they received commissions. ${ }^{40}$

Third, the banks' securitisation of the mortgages provided an outlet for wealthy financiers that cried out for portfolio-investment opportunities. Thus in the relatively short period from 2000 to 2007 , the securities issuance of banks in the USA and Europe quadrupled from US $\$ 400$ to nearly US $\$ 1600$ billion. ${ }^{41}$

The behaviour of banks resulted in the postponement of stagnation and a vastly increased share of surplus-value (operating surplus) in GDP. However, along with the mortgage-driven housing market bubble that the postponement evoked, it also laid the minefield of risky assets. Once this process of postponement of stagnation was well under way, there were no sensible institutions to prevent its continuation: neither central banks nor other supervising authorities, nor governments. States had declared the 'independence' of central banks, while central banks - as intertwined with commercial banks via personal ties declared 'self-regulation' for commercial banks. Commercial bankers may not have sat at the Basel assemblies, but they were important consultants for its

39 Note that if consumer credit is provided by the enterprises themselves - or specialised branches thereof - the enterprises would require a PVF for that credit. Hence this case ultimately reduces to a sub-case of that of Sheet 3.10.

In a report from the Basel Committee on Banking Supervision it is calculated that over the 15 years preceding the crisis (1993-2007), banks secured an (after tax) average rate of profit of $14.8 \%$ on their own capital. See 'An assessment of the long-term economic impact of stronger capital and liquidity requirements', BIs, August 2010, p. 48. http://www .financialstabilityboard.org/publications/r_10o818a.pdf.

This is amplified upon by Lysandrou 2009. 
weak 'framework' and weaker performance. (In this respect all this is not alien to the constellation of private 'Clearing Banks' as presented in Chapter 2 and onwards in Part One.)

\section{$5^{\mathrm{A}-4}$ Course of the 2008 crisis and its crisis-ridden aftermath}

The course of the crisis itself is not particularly difficult to follow, and it has been detailed at great length in the literature. Because most banks were weak on the assets side of their balance sheet, they had reason to distrust other banks in that respect. Once one or several main banks got into actual trouble i.e. insurmountable debts to other banks - the distrust domino-ed around the world, affecting the USA and the EU most directly. Ultimately even the banking system as a system of money transfer (payments) nearly collapsed: banks did not want to receive payments from other distrusted banks as this puts the one bank in risky debt with the other. States ultimately had to step in, nationalising or semi-nationalising major banks, so as to at least preserve the payments system.

In sum, enterprises and banks had no choice but to accept reduced profits. The portfolio investors who had bought the securitised loans were the least affected group because banks had generally provided off-balance sheet guarantees. The biggest misery was imposed on the increasing numbers of the unemployed, with still-employed workers in a close second spot, facing wage cuts and ultimately lower living standards through cuts of state-provided transfers.

\section{A-5 Problem of stagnation not resolved}

(Conclusions below apply to the state of affairs when I completed this book.)

The financial and economic crisis is the expression of the reaction to the substantial shifts in the distribution of income beginning around the early $198 \mathrm{os}$. However, the 2008 crisis and its aftermath have not resolved the problem of potential stagnation. On the contrary:

- If banks do not face more effective regulation than what has so far been proposed (when I completed this book), the banking system risks renewed collapse. A new round of massive state assistance, apart from being politically less likely, would once again encroach on the financial means of states. On the other hand, if banks are going to be effectively regulated, then the postponement of stagnation will come to an end: relative consumption will substantially decline as consumer credit stagnates and plays a lesser role in financing consumption.

- Besides this, we have the colonisation of the future labour incomes: income claims that will also result in a relative decline of consumption. 
- With a relative decline in consumption, the investment of enterprises will also slacken. ${ }^{42}$

In sum, the economies of the USA and the EU are likely to enter a period of stagnation.

\section{A-6 Modification of the 'normal' course of the business cycle}

As remarked in the introduction to this appendix, along with the period of structural change (i.e. from the early 1980 s to 20o8) we had the 'normal' cyclical alternation, though with modifications. These regard the destination of the PVF (shifting from enterprises towards labour), the sources of savings (shifting from wages towards capital owners) and the diverse effect of these on the $\triangle \mathrm{RPVF}$ (even if the sum of the $\triangle \mathrm{RPVF}$ may not have been much affected).

Regarding the outline of the cycle presented in Chapter 5 , it should first of all be recalled that the outline refers to a constellation with the state bracketed. As we will see in Chapter $10\left(1 \circ D_{1}\right)$, this has a main effect on the cycle's amplitude to the extent that the state impacts as an (automatic) stabiliser. In face of unemployment benefits it also affects the degree of savings decrease by labour in the crisis and recession.

That said, refer to the stylised summary of Figure 5.7. Generally, the structural change referred to flattens the cyclical changes in Sw. On the other hand, because of the structurally increased distributed capital income, the Sk effects are reinforced. These savings differences also affect their impact on the RPVF. These do not seem to have major effects on the directions of the change in the core determinants of investment, that is, the rate of internal profit $(\rho)$ and the rate of overcapacity (ø).

Given that the income of capital owners is rather functionless (whilst their consumption acts as an automatic stabiliser, their savings are not only nonnecessary but also make the RPVF increasing), a restoring re-shift in the distribution of income could prevent stagnation. ${ }^{43}$ However, in case of an effect-

42 An additional and vast 'deepening investment' might in principle keep up investments but there seems to be no market incentive for these to come about at just the right time, in large enough amounts. An obvious field for such investments might be that of non-conventional energy. A 'market' incentive for that might be a heavy taxation on conventional energy. The problem with such a solution is that this would further depress consumption in the following two decades - and hence non-deepening investment. Such a programme would have to be combined with an intensification of the measures discussed in the next section.

43 The first part of this sentence is reminiscent of one of Keynes's judgements: 'I see therefore, the rentier aspect of capitalism as a transitional phase which will disappear when it has done its work. ... [T] he euthanasia of the rentier, the functionless investor [presum- 
ive stagnation via consumption decrease, much depends on its pace. A fast decrease would tend to take the economy into depression. At a slow decrease, such that at least an on average poor rate of macroeconomic growth is maintained, cyclical movements would tend to be imposed on that poor rate of growth.

\section{Appendix $5^{B}$. Stratified production and Marx's unfinished theory of the cycle}

As indicated in Addendum 5§9-a, Marx presents his exposition of the cyclical movement of capital in Capital I, Part Seven and in Capital III, Part Three. ${ }^{44}$ Although I have taken much inspiration from Marx's treatment of the matter, his exposition is quite different from the one presented in Chapter 5 , mainly because he systematically introduces finance only after the cyclical movement - as specified below.

Marx's first treatment (Capital I) - as he is very much aware - is based purely on the production and accumulation of capital, without having systematically presented at that point: the (any) rate of profit; the expenditure side of the economy; banking and finance.

When Marx reaches his second treatment (Capital III) he has developed the rate of integral profit (surplus-value based), though he has still bracketed expenditure, banking and finance. ${ }^{45}$ Thus in Marx's systematic he would have to return to the business cycle after his treatment of banking and finance (the second half of the current Capital III). Alas, however, he did not reach this in his lifetime. Therefore Marx's theory of the cyclical movement of capital is an incomplete one.

Even so, insight is to be gained from an abstract treatment such as Marx's that we have. I briefly expand on Marx's second treatment. (In comparison with Chapter 5 all effects of external finance (the RPVF and $i \varepsilon \mathrm{K}$ ) and of saving in relation to expenditures are thus bracketed.) Marx focuses on surplus-value, the rate of integral profit, accumulation and technical development.

ably he means financier or portfolio investor], will be nothing sudden, merely a gradual but prolonged continuance ... and will need no revolution' (Keynes 1936, p. 376).

44 Marx 1976 [1867] and 1981 [1894].

45 This is so in his last manuscript on the matter. Presumably he planned to include the expenditures side that he had developed largely after that manuscript in his manuscript for the last part of Volume II of Capital. 
Marx's view on technical development is that this of a $\mathrm{K} / \mathrm{wL}$ rising type. Then, assuming that the rate of surplus-value $(\Pi / \mathrm{wL})$ is more or less constant in the upturn, he has for the upturn:

$$
\omega=\frac{\Pi}{\mathrm{K}}=\frac{\Pi / \mathrm{wL}}{\mathrm{K} / \mathrm{wL}} \frac{\text { (roughly constant in upturn) }}{\text { (rising in upturn) }}
$$

As a result the rate of integral profit $(\omega)$ declines in the upturn. Then, what I called 'restructuring of capital' in the downturn (destruction and devaluation of capital) restores the rate of profit, whence - as Marx expresses it - 'we go round the whole circle once again', a vicious circle ('Zirkel vicieux'). ${ }^{46}$ This rate of profit curing effect of the recession reveals Marx's tremendously impressive insight of the matter (one that also impressed Schumpeter, as indicated in $5 \S 9-\mathrm{a}) \cdot{ }^{47}$

Some critics of Marx have questioned this presentation on the grounds that micro foundations are lacking for it. In their view, capitalists would not generally introduce rate of profit decreasing techniques of production. ${ }^{48}$ I have indicated (Reuten 1991) that from the perspective of a stratified structure of production, it is quite feasible that new techniques have a rate of profit decreasing effect for a sector or the economy at large. ${ }^{49}$ I should now add that this is especially the case in a constellation of price competition. (Compare $4 \mathrm{D}_{2}$ where the price-leader introduces a new technique - perhaps a K/wL rising one - whence for the totality of the stratification the rate of profit declines.) From this perspective the critic alluded to can be refuted.

However, further scrutiny of Marx's theory indicates that it is quite compatible with a more general theory of over-accumulation of capital, one of either a $\mathrm{K} / \mathrm{wL}$ increasing or a $\mathrm{K} / \mathrm{wL}$ decreasing type of technical change (as I remarked in my 1991 paper). This more general theory has been presented in Chapter 5 , including the main complexities of finance and expenditures (via savings), which affect the distinct movement of the various phases of the cycle.

46 Marx 1993 [ms. 1864-65], p. 329; cf. the somewhat deviating formulations for 'Zirkel vicieux' in Marx 1964 [1894 ed. Engels], p. 265 and 1981 [1894 ed. Engels, English translation], p. 364. In studying the cycle Marx gradually developed this view. Along with it he put increasing emphasis on the rate of profit restoring character of the recession. See Reuten and Thomas 2011, and Thomas and Reuten 2013. Note also that in Engels's edition of Marx's manuscript for Capital III, there are significant changes (by Engels) that deemphasise the restorative role of the recession (Reuten $2004 \mathrm{c}$; this article also provides a commented general outline of the three chapters constituting Marx's theory of the cycle in Capital III).

48 See the references in Reuten 1991.

49 Cf. Reuten and Williams 1989, Chapter 4. 


\section{List of figures chapter 5}

Scheme 5.1 The cyclical over-accumulation and destruction of capital (outline chapter 5) 246

\section{5§6. A condensed macroeconomic sequence}

Figure 5.2 Condensed macroeconomic sequence of production and profit determination 254

Graph 5.3 Change of GDP and recessions in the USA 1950-2015 255

5§7. The phase-wise stratified cyclical movement of capital: preliminaries Figure 5.4 Stylised shape of one business cycle 257

Figure 5.5 Phase-wise macroeconomic stratification of capital 258

5§8. Cyclical movement (1): from expansion to stagnation

Figure 5.6 Simple summary of the cyclical movement of capital: expansion and contraction 262

Figure $5 \cdot 7$ Stylised summary of the cyclical movement of capital 263

Appendix 5A. On the particular structural background of the 2008 crisis

Graph 5.8 Macroeconomic income and expenditure shares in GDP: EU-15 and USA 1960-2010 283 